TI 2018-006/VI

Tinbergen Institute Discussion Paper
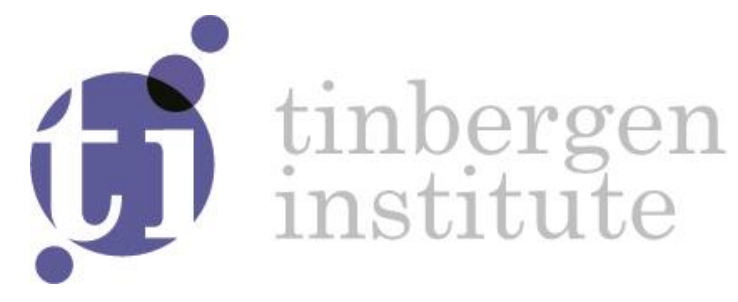

\title{
Unclogging the Credit Channel: On the Macroeconomics of Banking Frictions
}

\section{Revision: February 12, 2018}

Egle Jakucionyte ${ }^{1}$

Sweder van Wijnbergen ${ }^{2}$

\footnotetext{
${ }^{1}$ Central UvA, Bank of Lithuania

2 UvA, CEPR, DNB
} 
Tinbergen Institute is the graduate school and research institute in economics of Erasmus University Rotterdam, the University of Amsterdam and VU University Amsterdam.

Contact: discussionpapers@tinbergen.nl

More TI discussion papers can be downloaded at http://www.tinbergen.nl

Tinbergen Institute has two locations:

Tinbergen Institute Amsterdam

Gustav Mahlerplein 117

1082 MS Amsterdam

The Netherlands

Tel.: +31(0)205984580

Tinbergen Institute Rotterdam

Burg. Oudlaan 50

3062 PA Rotterdam

The Netherlands

Tel.: +31(0)10408 8900 


\title{
UnClogging the CRedit Channel: on the
}

\section{MACROECONOMICS OF BANKING FRICTIONS*}

\author{
Egle Jakucionyte ${ }^{\dagger}$ and Sweder van Wijnbergen ${ }^{\ddagger}$
}

February 12, 2018

\begin{abstract}
We explore the consequences of different financial frictions on the corporate and banking level for macroeconomic policy responsiveness to major policy measures. We show that both corporate and bank debt overhang reduce the effectiveness of fiscal policy: multipliers turn negative with debt overhang in either sector. The negative impact of banking frictions on macro outcomes increases when a larger part of working capital is financed through credit in addition to investment. Debt overhang in banks leads to positive NPV loans being rejected; but after banks increase their equity ratio and subsequently engage less in risk shifting behavior, a decline in lending emerges. Thus the macroeconomic response to higher capital requirements depends on which friction is dominant: when there is debt overhang in banks higher capital leads to more, not less loans and is expansionary; while higher capital requirements lower loan volumes and have a recessionary impact when risk shifting is the problem in banks. We trace the differential importance of corporate versus banking debt overhang back to the different approaches followed on each side of the Atlantic in response to the undercapitalization of the banks after the onset of the financial crisis. We similarly trace macrodevelopment differences in the Southern periphery of Europe and the Northern European countries to differences in the problems and policies in their financial sector.

Key Words: Banking frictions, Fiscal Policy, Capital Requirements, volatility Shocks

JEL Codes: E44, E58, E62, G18, G21

\footnotetext{
${ }^{*}$ We are indebted to Frederic Malherbe and Christian Stoltenberg for helpful discussions and to Peter van Els

†Tinbergen Institute and the University of Amsterdam, the Netherlands.

${ }_{\ddagger}^{\ddagger}$ Tinbergen Institute, CEPR and the University of Amsterdam, the Netherlands.
} and other seminar participants at DNB for comments. We are indebted to DNB for financial support for this research. The views expressed here do not represent the views of DNB.
\end{abstract}




\section{Introduction}

The macro responses to policies after the Great Financial Crisis (GFC) struck now some ten years ago have been of a bewildering variety. Expansionary fiscal policy seems to have worked well in the early Obama years in the US but has singularly failed in several European countries. But a large fiscal expansion following the Lehman fiasco failed to have any impact on GDP in the Netherlands, and large deficits in Greece actually triggered a second Europe-wide crisis in 2011 and an unparalleled recession in Greece itself. On the other hand Germany immediately adopted contractionary fiscal policies but was the best performer in terms of GDP growth in the early years after the GFC spilled over into Europe from the US. Finally the refusal to impose budget discipline in France has not averted worse than average performance by the French economy in the years following Lehman. The same seemingly contradictory patterns have emerged on both sides of the Atlantic when one looks at the recovery (or absence thereof) of bank lending to the corporate sector, in spite of the fact that both the US and Europe have seen substantial improvements in the capitalization ratio of their commercial banks.

The precise nature of banking and corporate frictions is likely to matter a great deal for another policy debate too, the debate about whether the ECB's attempts at "unclogging the credit channel" were ineffective for not addressing the root cause of the moribund performance of commercial bank lending to the corporate sector. Although a precise analysis of the ECB's LTRO and TLTRO programs will be analyzed in a companion paper with more explicit modeling of monetary policy instruments, the impact of recapitalization under various frictions may already shed light on this issue too. Whether banks or firms are facing debt overhang, or whether banks in fact are withdrawing from excessive risky lending is more than likely to matter for an evaluation of the ECB's policies aimed at reviving commercial bank credit.

We argue in this paper that differential frictions can play a role in explaining diverging experiences and trace the differences back to the policy interventions chosen in response to the GFC. Debt overhang, both when it occurs in the corporate sector and when it plays out in the banking sector, much reduces the effectiveness of fiscal policy, to such an extent that it actually becomes contractionary. A recap is called for when there is bank debt overhang, but will not do much when there is corporate debt overhang. But we then delve deeper into banking frictions and show that higher capitalization may lead to both more or less lending depending on whether the underlying friction is debt overhang or excessive risk shifting triggered by low capitalization in combination with limited liability, with as a consequence opposite macroeconomic impact of the higher capital ratios in the two cases. Thus the different prevalence of different frictions may well explain both the diverging experience with fiscal stimuli in the US versus (parts of) Western Europe: US recaps eliminated debt overhang and thus made fiscal policy more 
effective, while Europe's failure to decisively deal with bank capital shortages undermined the incidental fiscal expansions that did take place.

And the analysis of different frictions within the banking system may clarify different macrodevelopments in Northern Europe and in the Southern Periphery. This is relevant because the source of frictions in the banking system is very different in the northern Eurozone country than it is in the periphery countries. Banks in countries like the Netherlands or Germany have seen negligible worsening of their loan portfolios coupled with a substantial improvement in their capitalization: as a consequence one should expect a decline in risk shifting and a decline in lending, but that is in fact socially optimal: if risk shifting is the predominant mechanism, previously banks took on too much risk. On the other hand in the periphery countries non-performing loans (NPLs) have skyrocketed to percentages not earlier seen in advanced countries, suggesting that the periphery the problem was debt overhang in the banking system. The associated decline in loan volume does present a social loss in that case. In line with that diagnosis one would expect loan volumes to decline further in the North but recover in the periphery in response to raising capital requirements further. ${ }^{1}$ We venture that these issues should also be considered in any analysis of the sluggish response to the ECB's policies aimed at reviving bank credit to the corporate sector.

To analyze all these puzzles and reach the conclusions summarized in the previous paragraph we introduce several banking frictions in an otherwise standard New-Keynesian macro model. The model deviates from a New-Keynesian DSGE tradition in the way we model corporate borrowers and banks. The corporate sector faces debt overhang. We explicitly consider debt overhang in the corporate sector versus frictions on the liability side of banks' balance sheets; of the latter we distinguish between debt overhang (negative shocks on old loans) and excessive risk shifting in the banking sector because of low capitalization in combination with limited liability; excessive risk shifting refers to too much risk taking in new loans. This allows us to address the issues perennially debated between corporates complaining about a lack of loan supply versus banks arguing that they are not offered projects with a return attractive enough to compensate for higher risk. In the latter view lending is stagnant because contrary to prior to the crisis risk is now adequately priced in and loan requests that are rejected are rejected because they are excessively risky. There are two variants of the model, one features risk-shifting and another introduces bank debt overhang. We use these two model variant to demonstrate the differences in policy response under different financial frictions. An obvious take away for policy makers and their (quantitative) advisors is that paying attention to financial frictions and in particular to their "location", i.e. it matters between which parties what sort of friction exists, is of essential importance for correct predictions of

\footnotetext{
${ }^{1}$ If these higher requirements are met by actually raising fresh capital instead of leaving the decision to the banks themselves; cf van der Kwaak and van Wijnbergen (2017).
} 
sometimes even the sign, let alone the magnitude, of the impact of a large array of commonly used policy measures.

\section{Related literature}

There has been an outburst of interest in banking frictions in macroeconomic models in the years since the GFC burst on the scene in 2007-2008. In fact some preceded the crisis (Bernanke and Gertler (1989); Bernanke et al. (1999) (BGG) are the best known examples) but the real surge has happened since the GFC. Brunnermeier et al. (2012) provide an exhaustive survey. Most subsequent papers (e.g. Clerc et al. (2011)) follow either the BGG approach to frictions between banks and their borrowers or assume borrowing constraints in the spirit of Kiyotaki and Moore (1997). We take a different approach by basing our analysis of corporate debt overhang on the classic paper by Merton (1974) (of course one should also mention Myers (1977)). The key difference between these two approaches lies in the assumptions made on contractibility. In BGG monitoring costs are imposed on borrowers so as to guarantee truth telling about project outcomes, but because there is complete contractibility no moral hazard problems arise. In the Merton (1974) approach investment and hirings are not contractible, with moral hazard issues arising as a consequence. For earlier papers introducing Merton-like debt overhang in a macroenvironment see Jakucionyte and van Wijnbergen (2017) and for a similar earlier example Occhino and Pescatori (2015). Indebted firms face lower incentives to invest and hire labor when unanticipated net resource outflows have led to a stock of arrears on existing debt with prior claim on any new cashflows, a situation for which Myers (1977) coined the phrase debt overhang. Indebted firms reject projects with a positive present value because (part of) the return is seized by these creditors rather than shareholders. Empirical investigation of the presence zombie firms in the European periphery and implications for growth is provided in Acharya et al. (2016) and McGowan et al. (2017).

The Merton put option approach to financial frictions between lender and borrower leads to another novelty in the paper. Despite using first-order approximation techniques to solve the resulting DSGE, volatility does have a first order impact on model outcomes because volatility shows up in the derivatives of that Merton put with respect to corporate investment and employment, in the same way volatility has an impact on general option derivatives ("the Greeks"), so we can use our model to study the impact of volatility shocks in spite of using a first order approach to solving the model. The volatility related put option term in the financially constrained firms' optimization problem drives a wedge between social and private benefits from investing. Besides modeling a shock to the volatility of an exogenous process in firms' future profits, we endogenize overall volatility by incorporating uncertainty about prices: we simulate the model going back and forth between assumed and generated volatility until the two converge, thus endogenizing the overall volatility of corporate profits ${ }^{2}$. The obtained volatility value contains more

\footnotetext{
${ }^{2}$ We thank Christian Stoltenberg for suggesting this numerical approach to endogenizing volatility.
} 
information about the propagation of a particular shock in our model and thus is superior to an arbitrarily calibrated value.

Banks can suffer from debt overhang too. A high level of non-performing loans on bank balance sheets can for exactly the same reason prevent banks from raising new equity to fund projects with a positive net present value. The reason is the same as with firms: banks will then take into account that much of the lending value would be seized by bank creditors. The bank debt overhang problem is provided as a reason for regulatory intervention in the context of the Great Recession in Hanson et al. (2011). Occhino (2017a) analyzes the Eurozone crisis and policy response by showing how bank debt overhang and public debt overhang can reinforce each other and create multiple equilibria. Bahaj and Malherbe (2016) analyze these different frictions using a partial equilibrium model of the banking sector. As they point out it is not clear whether lower lending is suboptimal without knowing what the dominant friction is: If banks engaged in risk shifting, a decline in lending would mean that banks are not taking projects with a negative present value. If banks faced debt overhang instead, a decline in bank lending would prevent projects with a positive net present value from getting funded. Gaining insight into which is the dominating friction in banks would offer different policy implications.

All of the literature (with the exception of Bahaj and Malherbe (2016)) focuses on a relatively narrow, although obviously important, question, whether financial frictions work as amplification mechanisms for monetary policy (cf the survey in Brunnermeier et al. (2012)). We add to that literature by explicitly focusing on the interaction between various type of financial frictions on the one hand and general macroeconomic policy measures such as fiscal policy or raising capital requirements for banks.

Section 2 presents the model. Section 3 demonstrates the workings of the model and analyzes the suggested explanations for low credit growth. We show in particular how the macroeconomic response to respectively fiscal policy, higher capital requirements and monetary policy is influenced by various financial frictions. Section 4 concludes.

\section{Model}

In this section we describe the model, focusing in detail on the specific modeling of the various frictions. Exposition of the more standard parts of the model is sketched in outline only, with details left to the appendix D. Different versions of the model eliminate one or more of the frictions; we also explore the consequences of different assumptions about the short run flexibility of labor demand. 


\section{$2.1 \quad$ Households}

We assume a representative household. The household puts deposits $d_{t}$ in a bank and supplies labor $h_{t}$ in a competitive labor market. The household chooses a level of real consumption $c_{t}$ and working hours $h_{t}$ so as to maximize lifetime utility

$$
E_{0} \sum_{t=0}^{\infty} \beta^{t}\left(\frac{\left(c_{t}\right)^{1-\sigma}}{1-\sigma}-\frac{\chi\left(h_{t}\right)^{1+\varphi}}{1+\varphi}\right) \quad \sigma, \chi, \varphi>0
$$

subject to the household's budget constraint, expressed in units of composite goods:

$$
c_{t}+d_{t}+n_{t}+p_{t}^{e} e_{t}=w_{t} h_{t}+\frac{R_{t-1}}{\pi_{t}} d_{t-1}+\Pi_{t}
$$

$\pi_{t}$ denotes the composite goods price inflation. $R_{t}$ is nominal gross interest rate on deposits. The household supplies banks with predetermined equity, $n_{t}$ (defined in nominal terms as $N$ ). Also, the household buys new bank equity $e_{t}$ at a real price $p_{t}^{E}$. The household owns all firms and banks in the model economy and receives total lump-sum profits, $\Pi_{t}$. Profits consist of profits made by firms and profits made by banks.

\subsection{Debt overhang in the banking sector}

This section explores debt overhang in the banking sector which arises due to old loans on the bank balance sheet. The modeling framework loosely follows Occhino (2017b).

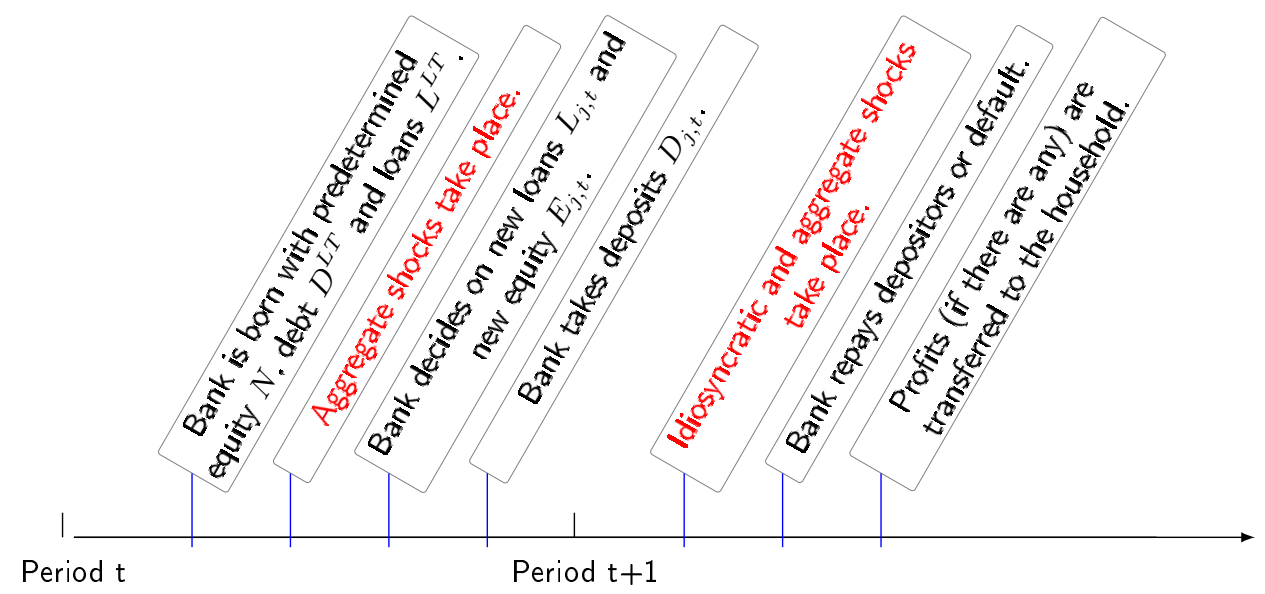

Figure 1: The periods $t$ and $t+1$ timeline for bank $j$ (which belongs to the generation $t$ ).

Banks operate for two periods only but new banks enter the market every period so there is always a continuum of these banks. In the second period some of the banks may default. Banks that do not default transfer their profits to the household. In the beginning of their "lives" banks are identical; but 
in the next period they are subject to idiosyncratic portfolio shocks $\omega_{j, t+1}$ that affect returns on old loans ${ }^{3}$. This assumption facilitates aggregation across banks. Debt overhang arises due to old loans on bank balance sheets. Banks start with a stock of predetermined loans which may receive a negative shock to the exogenous real return on old loans $r_{t}^{L T}$. A negative return shock increases the bank default probability and, for the reasons mentioned before, reduces bank incentives to issue new loans.

The detailed sequence of banks' decisions is presented in the timeline (Figure 1). Banks start their life with old loans $l^{L T}$ contracted in real domestic terms (this assumption allows us to make these loans inflation risk free). Also they have old equity $N$ and old deposits $D^{L T}$ such that $N+D^{L T}=L^{L T}$. We assume that the bank finances new loans $L_{j, t}$ to financially constrained firms by collecting deposits or issuing new equity $E_{j, t}$ at a nominal price $P_{j, t}^{E}$. Returns after paying depositors are shared between old shareholders and new shareholders in proportion to their respective number of shares ${ }^{4}$. Deposits pay a nominal gross interest rate $R_{t}$ and the nominal gross return on new loans is $R_{j, t}^{L}$.

Then maximum profits of a bank $j$ from the generation $t$ can be expressed in prices of composite goods:

$\left.\max _{\left\{L_{j, t}, D_{j, t}, E_{j, t}\right.}\right\} \quad \frac{N}{N+E_{j, t}} E_{t} \beta \Lambda_{t, t+1}\left\{\frac{\omega_{j, t+1} r_{t}^{L T} l_{t}^{L T} P_{t+1}+R_{j, t}^{L} L_{j, t}-R_{t} D_{j, t}-R_{t} D^{L T}}{P_{t+1}}, \quad 0\right\}-\frac{P_{j, t}^{E} E_{j, t}}{P_{t}}$

The bank can choose $D_{j, t}, E_{j, t}$ and $L_{j, t}$ and has to satisfy the following constraints:

$$
\begin{array}{cr}
\frac{P_{j, t}^{E} E_{j, t}+D_{j, t}}{P_{t}}=\frac{L_{j, t}}{P_{t}}, & \text { (Balance sheet constraint) } \\
\frac{P_{j, t}^{E} E_{j, t}}{P_{t}}=\gamma \frac{L_{j, t}}{P_{t}}, \quad \gamma \in(0,1) & \text { (Leverage constraint) } \\
N=\gamma l_{t}^{L T} P_{t}, \quad \gamma \in(0,1) & \text { (Leverage constraint for old loans) }
\end{array}
$$

Plugging in the balance sheet constraint to substitute deposits and the leverage sheet constraint to substitute new equity $E_{j, t}$ gives

$$
\begin{gathered}
\max _{L_{j, t}} \frac{P_{j, t}^{E} N}{P_{j, t}^{E} N+\gamma L_{j, t}} E_{t} \beta \Lambda_{t, t+1}\left\{\frac{R_{j, t}^{L} L_{j, t}+\omega_{j, t+1} r_{t}^{L T} l_{t}^{L T} P_{t+1}-R_{t}(1-\gamma)\left(L_{j, t}+l_{t}^{L T} P_{t+1}\right)}{P_{t+1}}, 0\right. \\
-\frac{\gamma\left(L_{j, t}+l_{t}^{L T} P_{t}\right)}{P_{t}}+\frac{N}{P_{t}}
\end{gathered}
$$

Next, we express variables in units of composite goods. We define $l_{j, t} \equiv L_{j, t} / P_{t}, l_{t}^{L T} \equiv L^{L T} / P_{t}$,

${ }^{3}$ The shock is assumed to be log-normally distributed to simplify derivations. Also, $E \omega=1$.

${ }^{4}$ Section B in the appendix describes the case where new shares are preferential shares like in Bahaj and Malherbe (2016). 
$n_{t} \equiv N / P_{t}$ and $n_{t} \equiv N / P_{t}$. It follows that

$\max _{l_{j, t}} \frac{p_{t}^{e} n_{t}}{p_{t}^{e} n_{t}+\gamma l_{j, t}} E_{t} \beta \Lambda_{t, t+1}\left\{\frac{R_{j, t}^{L}}{\pi_{t+1}} l_{j, t}+\omega_{j, t+1} r_{t}^{L T} l_{t}^{L T}-\frac{R_{t}}{\pi_{t+1}}(1-\gamma)\left(l_{j, t}+l_{t}^{L T}\right), \quad 0\right\}-\gamma\left(l_{j, t}+l_{t}^{L T}\right)+n_{t}$

Further, we rearrange terms to:

$$
\begin{aligned}
\max _{l_{j, t}} \frac{p_{t}^{e} n_{t}}{p_{t}^{e} n_{t}+\gamma l_{j, t}} \quad & E_{t} \beta \Lambda_{t, t+1}\left\{\omega_{j, t+1} r_{t}^{L T} l_{t}^{L T}-\min \left\{\frac{R_{t}}{\pi_{t+1}}(1-\gamma)\left(l_{j, t}+l_{t}^{L T}\right)-\frac{R_{j, t}^{L}}{\pi_{t+1}} l_{j, t}, \quad \omega_{j, t+1} r_{t}^{L T} l_{t}^{L T}\right\}\right\} \\
& -\gamma\left(l_{j, t}+l_{t}^{L T}\right)+n_{t}
\end{aligned}
$$

For a moment, we focus on the minimum term only:

$$
\min \left\{\omega_{j, t+1} r_{t}^{L T} l_{t}^{L T}, \quad \frac{R_{t}}{\pi_{t+1}}(1-\gamma)\left(l_{j, t}+l_{t}^{L T}\right)-\frac{R_{j, t}^{L}}{\pi_{t+1}} l_{j, t}\right\}
$$

If the inflation term is factored out from the right hand side, the term can be summarized as $\min \left\{y_{t+1}, d\right\}$ where $y_{t+1}$ is a stochastic variable and $d$ is predetermined. It follows that

$$
E_{t} \min \left\{y_{t+1}, d\right\}=\left(1-\Phi\left(d_{1, t}\right)\right) E_{t} y_{t+1}+\Phi\left(d_{2, t}\right) d
$$

where $\Phi\left(d_{2, t}\right)$ models the bank survival probability and

$$
d_{2, t} \equiv \frac{E_{t} \ln \left(y_{t+1}\right)-E_{t} \ln (d)}{\sigma_{B}}, \quad d_{1, t} \equiv d_{2, t}+\sigma_{B}
$$

Finally we make use of the derived expressions to formulate the Lagrangian for the bank $j$ as

$$
\begin{aligned}
L=\max _{\left\{l_{j, t}\right\}} \frac{p_{t}^{e} n_{t}}{p_{t}^{e} n_{t}+\gamma l_{j, t}} & E_{t} \beta \Lambda_{t, t+1}\left(\omega_{j, t+1} r_{t}^{L T} l_{t}^{L T}\right) \\
& -E_{t} \beta \Lambda_{t, t+1}\left\{\left(1-\Phi\left(d_{1, t}\right)\right)\left(\omega_{j, t+1} r_{t}^{L T} l_{t}^{L T}\right)\right\} \\
& -E_{t} \beta \Lambda_{t, t+1}\left\{\Phi\left(d_{2, t}\right)\left(\frac{R_{t}}{\pi_{t+1}}(1-\gamma)\left(l_{j, t}+l_{t}^{L T}\right)-\frac{R_{j, t}^{L}}{\pi_{t+1}} l_{j, t}\right)\right\} \\
& -\gamma\left(l_{j, t}+l_{t}^{L T}\right)+n_{t}
\end{aligned}
$$

$\Phi\left(d_{2, t}\right)$ models the bank survival probability where

$$
d_{2, t} \equiv \frac{E_{t} \ln \left(\omega_{j, t+1} r_{t}^{L T} l_{t}^{L T}\right)-E_{t} \ln \left(\frac{R_{t}}{\pi_{t+1}}(1-\gamma)\left(l_{j, t}+l_{t}^{L T}\right)-\frac{R_{j, t}^{L}}{\pi_{t+1}} l_{j, t}\right)}{\sigma_{B}}
$$


and

$$
d_{1, t} \equiv d_{2, t}+\sigma_{B}
$$

Solving the Lagrangian problem gives the first-order condition that governs the issuance of new loans:

$$
\begin{gathered}
l_{j, t}: \quad \beta E_{t} \Lambda_{t, t+1}\left\{\Phi\left(d_{2, t}\right)\left\{\frac{R_{j, t}^{L}}{\pi_{t+1}}-\frac{R_{t}}{\pi_{t+1}}(1-\gamma)\right\}-\frac{\Phi^{\prime}\left(d_{2, t}\right)}{\sigma_{B}}\left\{\frac{R_{j, t}^{L}}{\pi_{t+1}}-\frac{R_{t}}{\pi_{t+1}}(1-\gamma)\right\}\right\} \\
=\gamma\left(1+2 \frac{\gamma l_{j, t}}{p_{t}^{e} n_{t}}\right)
\end{gathered}
$$

In equilibrium the first-order condition holds together with the balance sheet constraint and the leverage constraint:

$$
\begin{array}{rr}
n_{t}+p_{j, t}^{e} e_{j, t}+d_{j, t}+d_{t}^{L T}=l_{j, t}+l_{t}^{L T}, & \text { (Balance sheet constraint) } \\
n_{t}+p_{j, t}^{e} e_{j, t}=\gamma\left(l_{j, t}+l_{t}^{L T}\right), & \text { (Leverage constraint) } \\
n_{t}=\gamma l_{t}^{L T}, & \text { (Leverage constraint for old assets) }
\end{array}
$$

The new equity price is determined by the condition which sets the price equal to the expected value of the share of future returns that new shareholders get a claim to:

$$
\begin{aligned}
p_{j, t}^{e} e_{j, t}=\frac{e_{j, t}}{n_{t}+e_{j, t}} E_{t} \beta \Lambda_{t, t+1}\left\{\omega_{j, t+1} r_{t}^{L T} l_{t}^{L T}\right. & \\
& -\frac{e_{j, t}}{n_{t}+e_{j, t}} E_{t} \beta \Lambda_{t, t+1}\left\{\left(1-\Phi\left(d_{1, t}\right)\right)\left(\omega_{j, t+1} r_{t}^{L T} l_{t}^{L T}\right)\right\} \\
& -\frac{e_{j, t}}{n_{t}+e_{j, t}} E_{t} \beta \Lambda_{t, t+1}\left\{\Phi\left(d_{2, t}\right)\left(\frac{R_{t}}{\pi_{t+1}}(1-\gamma)\left(l_{j, t}+l_{t}^{L T}\right)-\frac{R_{j, t}^{L}}{\pi_{t+1}} l_{j, t}\right)\right\}
\end{aligned}
$$

\subsection{Risk shifting in the banking sector}

In this section we explore the risk shifting incentives that arise because of leverage in combination with limited liability for shareholders. Whether depositors require ex ante compensation for the risks that are shifted towards them will depend whether they are subject to deposit insurance or not, but is of no consequence once the deposit rate is set. We assume that the bank can collect deposits or issue new equity $E_{j, t}$ once again at the price $P_{j, t}^{E}$. New shareholders and old shareholders share returns proportionally to the respective number of shares they are holding.

New lending is risky because returns on new lending is affected by the idiosyncratic bank portfolio quality shock $\omega_{j, t+1}$. This shock is by assumption specific to the bank and unrelated to firms' performance; it can be interpreted as a shock to the quality/effectiveness of monitoring of loans leading to 
additional credit risk. The timing of other events and of bank choices is the same as in the case of bank debt overhang.

Then maximum profits of a bank $j$ from the generation $t$ can be expressed in prices of composite goods as:

$$
\max _{\left\{L_{j, t}, D_{j, t}, E_{j, t}\right\}} \frac{N}{N+E_{j, t}} E_{t} \beta \Lambda_{t, t+1}\left\{\frac{r_{t}^{L T} l_{t}^{L T} P_{t+1}+\omega_{j, t+1} R_{j, t}^{L} L_{j, t}-R_{t} D_{j, t}-R_{t} D^{L T}}{P_{t+1}}, \quad 0\right\}-P_{j, t}^{E} E_{j, t}
$$

The bank can choose $D_{j, t}, E_{j, t}$ and $L_{j, t}$ but subject to the following constraints:

$$
\begin{array}{lr}
\frac{N+P_{j, t}^{E} E_{j, t}+D_{j, t}+D_{t}^{L T}}{P_{t}}=\frac{L_{j, t}}{P_{t}}, & \text { (Balance sheet constraint) } \\
\frac{N+P_{j, t}^{E} E_{j, t}}{P_{t}}=\gamma \frac{L_{j, t}+l_{t}^{L T} P_{t}}{P_{t}}, \quad \gamma \in(0,1) & \text { (Leverage constraint) } \\
N=\gamma l_{t}^{L T} P_{t}, \quad \gamma \in(0,1) & \text { (Leverage constraint for old assets) }
\end{array}
$$

Plugging in the balance sheet constraint to substitute out deposits and the leverage sheet constraint to substitute out new equity $E_{j, t}$ gives

$$
\begin{gathered}
\max _{L_{j, t}} \frac{P_{j, t}^{E} N}{P_{j, t}^{E} N+\gamma L_{j, t}} E_{t} \beta \Lambda_{t, t+1}\left\{\frac{\omega_{j, t+1} R_{j, t}^{L} L_{j, t}+r_{t}^{L T} l_{t}^{L T} P_{t+1}-R_{t}(1-\gamma)\left(L_{j, t}+l_{t}^{L T} P_{t}\right)}{P_{t+1}}, \quad 0\right\} \\
-\frac{\gamma\left(L_{j, t}+l_{t}^{L T} P_{t}\right)}{P_{t}}+\frac{N}{P_{t}}
\end{gathered}
$$

Next, we express variables in units of composite goods. We define $l_{j, t} \equiv L_{j, t} / P_{t}, l_{t}^{L T} \equiv L^{L T} / P_{t}$, $n_{t} \equiv N / P_{t}$ and $n_{t} \equiv N / P_{t}$. It follows that

$$
\max _{l_{j, t}} \frac{p_{t}^{e} n_{t}}{p_{t}^{e} n_{t}+\gamma l_{j, t}} E_{t} \beta \Lambda_{t, t+1}\left\{\omega_{j, t+1} \frac{R_{j, t}^{L}}{\pi_{t+1}} l_{j, t}+r_{t}^{L T} l_{t}^{L T}-\frac{R_{t}}{\pi_{t+1}}(1-\gamma)\left(l_{j, t}+l_{t}^{L T}\right), \quad 0\right\}-\gamma\left(l_{j, t}+l_{t}^{L T}\right)+n_{t}
$$

Further, we express as

$$
\begin{aligned}
\max _{l_{j, t}} \frac{p_{t}^{e} n_{t}}{p_{t}^{e} n_{t}+\gamma l_{j, t}} \quad & E_{t} \beta \Lambda_{t, t+1}\left\{\omega_{j, t+1} \frac{R_{j, t}^{L}}{\pi_{t+1}} l_{j, t}-\min \left\{\frac{R_{t}}{\pi_{t+1}}(1-\gamma)\left(l_{j, t}+l_{t}^{L T}\right)-r_{t}^{L T} l_{t}^{L T}, \quad \omega_{j, t+1} \frac{R_{j, t+1}^{L}}{\pi_{t+1}} l_{j, t}\right\}\right\} \\
& -\gamma\left(l_{j, t}+l_{t}^{L T}\right)+n_{t}
\end{aligned}
$$

Further we use the result in equation (3) to get 


$$
\begin{aligned}
L=\max _{\left\{l_{j, t}\right\}} \frac{p_{t}^{e} n_{t}}{p_{t}^{e} n_{t}+\gamma l_{j, t}} & E_{t} \beta \Lambda_{t, t+1}\left(\omega_{j, t+1} \frac{R_{j, t}^{L}}{\pi_{t+1}} l_{j, t}\right) \\
& -E_{t} \beta \Lambda_{t, t+1}\left\{\left(1-\Phi\left(d_{1, t}\right)\right)\left(\omega_{j, t+1} \frac{R_{j, t}^{L}}{\pi_{t+1}} l_{j, t}\right)\right\} \\
& -E_{t} \beta \Lambda_{t, t+1}\left\{\Phi\left(d_{2, t}\right)\left(\frac{R_{t}}{\pi_{t+1}}(1-\gamma)\left(l_{j, t}+l_{t}^{L T}\right)-r_{t}^{L T} l_{t}^{L T}\right)\right\} \\
& -\gamma\left(l_{j, t}+l_{t}^{L T}\right)+n_{t}
\end{aligned}
$$

$\Phi\left(d_{2, t}\right)$ models the bank survival probability where

$$
d_{2, t} \equiv \frac{E_{t} \ln \left(\omega_{j, t+1} \frac{R_{j, t}^{L}}{\pi_{t+1}} l_{j, t}\right)-E_{t} \ln \left(\frac{R_{t}}{\pi_{t+1}}(1-\gamma)\left(l_{j, t}+l_{t}^{L T}\right)-r_{t}^{L T} l_{t}^{L T}\right)}{\sigma_{B}}
$$

and

$$
d_{1, t} \equiv d_{2, t}+\sigma_{B}
$$

Solving the Lagrangian problem gives the first-order condition that governs the issuance of new loans:

$$
\begin{aligned}
l_{j, t}: \quad \beta E_{t} \Lambda_{t, t+1} \quad & \left\{\Phi\left(d_{1, t}\right) \frac{R_{j, t}^{L}}{\pi_{t+1}}-\Phi\left(d_{2, t}\right) \frac{R_{t}}{\pi_{t+1}}(1-\gamma)\right. \\
& +\frac{1}{\sigma_{B}}\left(\Phi^{\prime}\left(d_{1, t}\right) \frac{R_{j, t}^{L}}{\pi_{t+1}}+\Phi^{\prime}\left(d_{2, t}\right) r_{t}^{L T} \frac{l_{t}^{L T}}{l_{j, t}}-\Phi^{\prime}\left(d_{2, t}\right) \frac{R_{t}}{\pi_{t+1}}(1-\gamma) \frac{l_{t}^{L T}}{l_{j, t}}\right) . \\
& \left.\cdot \frac{\frac{R_{t}}{\pi_{t+1}}(1-\gamma) l_{t}^{L T}-r_{t}^{L T} l_{t}^{L T}}{\frac{R_{t}}{\pi_{t+1}}(1-\gamma)\left(l_{j, t}+l_{t}^{L T}\right)-r_{t}^{L T} l_{t}^{L T}}\right\} \\
= & \gamma\left(1+2 \frac{\gamma l_{j, t}}{p_{t}^{e} n_{t}}\right)
\end{aligned}
$$

In equilibrium the first-order condition holds, as do the balance sheet constraint and the leverage constraint:

$$
\begin{gathered}
n_{t}+p_{j, t}^{e} e_{j, t}+d_{j, t}+d_{t}^{L T}=l_{j, t}+l_{t}^{L T}, \\
n_{t}+p_{j, t}^{e} e_{j, t}=\gamma\left(l_{j, t}+l_{t}^{L T}\right), \\
n_{t}=\gamma l_{t}^{L T}
\end{gathered}
$$

(Balance sheet constraint)

(Leverage constraint)

(Leverage constraint for old assets)

The new equity price is determined by the following condition, which equals the value of the new equity supplied to banks to the expected value of the corresponding share of future returns that new shareholders get. Assuming that returns are divided between old shareholders and new shareholders in proportion to their respective number of shares held gives: 


$$
\begin{aligned}
p_{j, t}^{e} e_{j, t}=\frac{e_{j, t}}{n_{t}+e_{j, t}} E_{t} \beta \Lambda_{t, t+1}\left\{\omega_{j, t+1} \frac{R_{j, t}^{L}}{\pi_{t+1}} l_{j, t}\right. \\
-\frac{e_{j, t}}{n_{t}+e_{j, t}} E_{t} \beta \Lambda_{t, t+1}\left\{\left(1-\Phi\left(d_{1, t}\right)\right)\left(\omega_{j, t+1} \frac{R_{j, t}^{L}}{\pi_{t+1}} l_{j, t}\right)\right\} \\
-\frac{e_{j, t}}{n_{t}+e_{j, t}} E_{t} \beta \Lambda_{t, t+1}\left\{\Phi\left(d_{2, t}\right)\left(\frac{R_{t}}{\pi_{t+1}}(1-\gamma)\left(l_{j, t}+l_{t}^{L T}\right)-r_{t}^{L T} l_{t}^{L T}\right)\right\}
\end{aligned}
$$

\subsection{Production and Pricing}

The production sector is modeled in a by now standard manner, with several types of firms active in the domestic economy. Capital producers produce the capital stock. Financially constrained firms buy their capital from capital producers and hire labor to produce homogeneous goods with capital and labor. Intermediate firms purchase these goods, costlessly differentiate the products bought and sell them as (local) monopolists, in Dixit-Stiglitz (1977) fashion. A composite goods producer buys the differentiated intermediate goods and aggregates them into the aggregate composite good $y_{t}$.

\subsubsection{Financially constrained firms}

Financially constrained firms may face debt overhang. Our modeling framework follows Merton (1974) who introduced the concept of debt overhang in corporate finance; see Occhino and Pescatori (2015) and Jakucionyte and van Wijnbergen (2017) for similar applications of the Merton approach in a business cycle model. Similarly to Jakucionyte and van Wijnbergen (2017) and in contrast to Occhino and Pescatori (2015), we allow the volume of corporate loans to vary over time rather than assume a fixed loan size. Financially constrained firms live for two periods. Every period there is a new-born generation of firms so the total number of firms always constitute a continuum of mass one. In the first period firms buy two types of inputs, capital $k$ and labor $h$ in advance, which generates their demand for working capital. Production takes place in the next period.

To pay in advance, a financially constrained firm $i$ borrows from the bank an amount $L_{i, t}$. To be able to borrow, the firm has to pledge future revenue as collateral. We assume that the firm decides how much to borrow before shocks arrive and the prices of production inputs are revealed. So loan demand equals the expected need for working capital. It follows that in the beginning of period $t$ the following condition holds:

$$
E_{t-1}\left\{l_{i, t}\right\}=E_{t-1}\left\{\left(q_{t} k_{i, t}+w_{t} h_{i, t}\right)\right\}
$$

where $q_{t}$ and $w_{t}$ denote the real price of capital and the real wage respectively. All prices are expressed 
in units of composite goods. After the loan is taken, shocks materialize, however, the predetermined size of the loan creates the debt overhang effect by distorting firm's private incentives to invest in production inputs.

Because of the timing of new information, the actual demand for working capital by the firm will in most cases not equal the loan amount received. Like Occhino and Pescatori (2015) we assume that in such cases the owner of the firm (the domestic household) steps in and transfers lump-sum funds $z_{i, t}$ to cover the difference. Importantly, these funds constitute residual funding and firms cannot rely on them ex ante as the main source of finance. These funds do enter the domestic household's budget constraint as a lump-sum transfer but have no impact on either the household's or the firm's incentives.

Let the matured loan be $R_{i, t}^{R}\left(\frac{l_{i, t}}{\pi_{t+1}}\right)$, where $R_{i, t}^{R}$ is the nominal gross interest rate on the loan. The bank sets interest rates on loans after the shocks take place, therefore, the loan rate adjusts to clear the loan market. The contracted collateral is firms' revenue from selling goods and depreciated capital in the next period, $p_{t+1}^{R} y_{i, t+1}^{R}+q_{t+1}(1-\delta) k_{i, t}$. Then the decision of the financially constrained firm $i$ born in period $t$ whether to default or not is determined by the lower value:

$$
\min \left\{R_{i, t}^{R} \frac{l_{i, t}}{\pi_{t+1}}, \quad\left(p_{t+1}^{R} y_{i, t+1}^{R}+q_{t+1}(1-\delta) k_{i, t}\right)\right\}
$$

where $p_{t+1}^{R} y_{i, t+1}^{R}=p_{t+1}^{R} A_{t+1} \theta_{i, t+1} k_{i, t}^{\alpha} h_{i, t}^{1-\alpha}$.

The firm maximizes the expected sum of future revenue from selling goods and (depreciated) capital minus debt payments. Financial flows received in period $t$ also enter the maximization problem and, as just explained, are equal to the difference between the loan plus equity $\left(z_{i, t}\right)$ and working capital expenditure:

$$
\begin{aligned}
\max _{\left\{k_{i, t}, h_{i, t}\right\}} & E_{t} \beta \Lambda_{t, t+1}\left\{p_{t+1}^{R} y_{i, t+1}^{R}+q_{t+1}(1-\delta) k_{i, t}\right\} \\
& -E_{t} \beta \Lambda_{t, t+1} \min \left\{R_{i, t}^{R} \frac{l_{i, t}}{\pi_{t+1}}, \quad \kappa\left(p_{t+1}^{R} y_{i, t+1}^{R}+q_{t+1}(1-\delta) k_{i, t}\right)\right\} \\
& +l_{i, t}+z_{i, t}-\left(q_{t} k_{i, t}+w_{t} h_{i, t}\right)
\end{aligned}
$$

s.t.

$$
E_{t-1}\left\{l_{i, t}\right\}=E_{t-1}\left\{\left(q_{t} k_{i, t}+w_{t} h_{i, t}\right)\right\}
$$

The resulting first-order conditions are: 


$$
\begin{aligned}
k_{i, t}: & E_{t} \beta \Lambda_{t, t+1}\left\{p_{t+1}^{R} \frac{\partial y_{i, t+1}^{R}}{\partial k_{i, t}}+q_{t+1}(1-\delta)\right\} \\
& -E_{t} \beta \Lambda_{t, t+1}\left\{\left(1-\Phi\left(d_{1, t}^{R}\right)\right)\left(p_{t+1}^{R} \frac{\partial y_{i, t+1}^{R}}{\partial k_{i, t}}+q_{t+1}(1-\delta)\right)\right\} \\
& =\frac{\partial \operatorname{cov}\left(\beta \Lambda_{t, t+1}, \quad \min \left\{R_{i, t}^{R} \frac{l_{i, t}}{\pi_{t+1}}, \quad\left(p_{t+1}^{R} y_{i, t+1}^{R}+q_{t+1}(1-\delta) k_{i, t}\right)\right\}\right)}{\partial k_{i, t}} \\
& +q_{t} \\
h_{i, t}: \quad & E_{t} \beta \Lambda_{t, t+1}\left\{p_{t+1}^{R} \frac{\partial y_{i, t+1}^{R}}{\partial h_{i, t}}\right\} \\
& -E_{t} \beta \Lambda_{t, t+1}\left\{\left(1-\Phi\left(d_{1, t}^{R}\right)\right)\left(p_{t+1}^{R} \frac{\partial y_{i, t+1}^{R}}{\partial h_{i, t}}\right)\right\} \\
& =\frac{\partial \operatorname{cov}\left(\beta \Lambda_{t, t+1}, \quad \min \left\{R_{i, t}^{R} \frac{l_{i, t}}{\pi_{t+1}}, \quad\left(p_{t+1}^{R} y_{i, t+1}^{R}+q_{t+1}(1-\delta) k_{i, t}\right)\right\}\right)}{\partial h_{i, t}} \\
& +w_{t}
\end{aligned}
$$

where

$$
d_{2, t}^{R} \equiv \frac{E_{t} \ln \left(\left(p_{t+1}^{R} y_{i, t+1}^{R}+q_{t+1}(1-\delta) k_{i, t}\right)\right)-E_{t} \ln \left(R_{i, t}^{R} \frac{l_{i, t}}{\pi_{t+1}}\right)}{\sigma_{R}}, \quad d_{1, t}^{R}=d_{2, t}^{R}+\sigma_{R}
$$

The debt overhang friction introduces an additional term in otherwise standard demand functions for capital and labor: the conditions incorporating the default probability $\left(1-\Phi\left(d_{1, t}^{R}\right)\right)$, because it reduces the marginal product of capital and labor. Thus the default probability drives a wedge between the social private benefits from investing. When the default probability increases, private benefits diminish and demand for labor and capital shrinks, resulting in a lower level of working capital than would be socially optimal.

The nominal gross interest rate $R_{t}^{R} i, t$ is related to bank return on corporate loans $R_{i, t}^{L}$ as follows:

$$
E_{t}\left\{\frac{R_{i, t}^{L}}{\pi_{t+1}} l_{t}\right\}=\Phi\left(d_{2, t}^{R}\right) E_{t} R_{i, t}^{R} \frac{l_{t}}{\pi_{t+1}}+\left(1-\Phi\left(d_{1, t}^{R}\right)\right) E_{t} \kappa\left(p_{t+1}^{R} y_{i, t+1}^{R}+q_{t+1}(1-\delta) k_{i, t}\right)
$$

\subsubsection{Intermediate firms}

A continuum of intermediate firms purchase goods from financially constrained firms at $p_{t}^{R}$. The firm $j$ 
differentiates its goods at no cost. Thus, in the second stage of firm $j$ problem, given nominal marginal costs, the firm chooses its price $p_{t}(j)$ to maximize profits. We assume that only a fraction $\left(1-\omega^{H}\right)$ of firms can adjust prices every period as in Calvo (1983). The fraction $\omega^{H}$ of remaining firms adjust past prices by the rate $\pi_{t}^{a d j}$. The aggregate price level that prevails in the retail sector is denoted by $p_{t}$. Differentiated goods from the domestic retail sector, $y_{t}(j), \quad j \in(0,1)$, are purchased by the composite goods producer.

\subsubsection{Composite goods}

Composite goods $y_{t}$ result from assembling differentiated production $y_{t}(j)$ for $j \in[0,1]$, each bought at price $P_{t}(j)$ and with no additional costs incurred. Let the aggregate price level of intermediate goods be $P_{t} \equiv\left(\int_{0}^{1}\left(P_{t}(j)\right)^{1-\epsilon_{H}} d j\right)^{1 /\left(1-\epsilon_{H}\right)}$. Then it follows that the demand for intermediate goods is given as a solution to the problem

$$
\max _{y_{t}(j)}\left\{P_{t} y_{t}-\int_{0}^{1} P_{t}(j) y_{t}(j) d j\right\}
$$

subject to the assembling technology

$$
y_{t}=\left(\int_{0}^{1} y_{t}(j)^{1-\frac{1}{\epsilon_{H}}} d j\right)^{\frac{\epsilon_{H}}{\epsilon_{H}-1}}
$$

As a result, optimal demand for intermediate goods of variety $j$ is given by

$$
y_{t}(j)=\left(\frac{P_{t}(j)}{P_{t}}\right)^{-\epsilon_{H}} y_{t}
$$

\subsubsection{Capital producers}

Capital producers sell capital to entrepreneurs at the real competitive price $q_{t}$ and buying the depreciated capital stock back next period. To restore the depreciated capital, capital producers add composite goods (investment) $i_{t}$ as additional inputs to the depreciated capital stock by using a technology subject to investment adjustment $\operatorname{costs} \Gamma\left(\frac{i_{t}}{i_{t-1}}\right)$ :

$$
k_{t}=(1-\delta) k_{t-1}+\left(1-\Gamma\left(\frac{i_{t}}{i_{t-1}}\right)\right) i_{t}
$$

where adjustment costs $\Gamma$ equal:

$$
\Gamma\left(\frac{i_{t}}{i_{t-1}}\right)=\frac{\gamma}{2}\left(\frac{i_{t}}{i_{t-1}}-1\right)^{2}
$$




\subsection{Monetary policy}

The central bank conducts monetary policy by following the Taylor rule:

$$
\frac{R_{t}}{\bar{R}}=\left(\frac{R_{t-1}}{\bar{R}}\right)^{\gamma_{R}}\left(\frac{y_{t}}{\bar{y}}\right)^{\left(1-\gamma_{R}\right) \gamma_{Y}}\left(\frac{\pi_{t}}{\bar{\pi}}\right)^{\left(1-\gamma_{R}\right) \gamma_{\pi}} \exp \left(m p_{t}\right)
$$

where $m p_{t}$ is a monetary policy shock.

\subsection{Market clearing}

The domestic household, the government and capital producers buy composite goods. Therefore, the supply of composite goods $y_{t}$ has to satisfy the aggregate demand of domestic agents:

$$
y_{t}=c_{t}+i_{t}+g_{t}
$$

\subsection{Endogenizing volatility}

We endogenize the volatility term to be able to incorporate uncertainty about prices. Also, in this way we provide support for the set value of the volatility term rather than calibrate it to an arbitrary value. We obtain the endogenized volatility value for future profits of financially constrained firms in the steady state by simulating the model until the value converges. Below we describe the simulation procedure as well.

As we pointed out before, the debt overhang wedge that distorts firms' decisions affect aggregate outcomes. However, the macroeconomic outcomes can also drive the default probability. Therefore, the default probability depends on fluctuations of prices as well and that is not captured by a fixed volatility term in the model approximated to the first order. Since the variance of endogenous variables is unknown, but we obtain an estimate from simulated series. In the supplementary appendix we derive what variance exactly we are interested in to be able to compute the default probability and simulate the model:

$$
\sigma_{R, t+1}^{2}=\operatorname{var}\left(\pi_{t+1} \kappa\left(p_{t+1}^{R} y_{i, t+1}^{R}+q_{t+1}(1-\delta) k_{i, t}\right)\right)
$$

Hence to simulate the model we need a numerical value for $\sigma_{R, t+1}^{2}$ or, more precisely, $\sigma_{R, t+1}$, where $\sigma_{R, t+1}=\sqrt{\sigma_{R, t+1}^{2}}$. We assume $\sigma_{R, t+1}$ to be constant $\left(\sigma_{R, t+1}=\sigma_{R}\right)$.

To find a value for $\hat{\sigma}_{y}$ as close to the true value as possible we follow several steps:

1. Set a threshold level for convergence of the calibrated $\hat{\sigma}_{y}$ to the value of $\tilde{\sigma}_{y}$ that follows from the simulated time series generated by the model. 
2. Choose an initial value for $\hat{\sigma}_{y}$.

3. Simulate the model for 1000 periods and 5 replication sets with the chosen value for $\hat{\sigma}_{y}$.

4. Compute volatility of $\bar{y}_{t+1}$ from simulated time series and denote it by $\tilde{\sigma}_{y}^{2}$.

5. Compute the difference between the chosen value $\hat{\sigma}_{y}$ and the simulated value $\tilde{\sigma}_{y}$. If the difference is larger than the threshold value, set $\hat{\sigma}_{y}=\tilde{\sigma}_{y}$ and repeat steps $3-5$.

We obtain the estimate of the volatility value in the model with both corporate DO and bank DO by drawing shocks from the distribution of the productivity shock and an exogenous shock to volatility, the standard deviations of which is 0.02 and 0.02 respectively. The estimate of the volatility value in the steady state $\left(0.0677^{2}\right)$ turns out to be very close to the previously calibrated variance of the shock and the variance of the shock to returns on old loans $\left(0.08^{2}\right)$.

\section{The model at work: slow credit growth and the macroe- conomic impact of bank recapitalization and fiscal and monetary policy}

\subsection{Are supply or demand factors constraining credit growth?}

Low credit growth in Europe has been explained by both low demand for credit (claimed by bankers) and low supply of credit (claimed by corporate executives). This section starts by examining recession outcomes with and without debt overhang in the corporate sector. Debt overhang for firms leads to both lower demand for labor and reduced investment spending, and thus leads to a reduced demand for credit. We proceed by comparing responses of the model variant with dominant corporate debt overhang to results generated with the model with bank debt overhang as a dominant factor restraining credit growth.

The two alternative explanations for a decline in credit (slowdown in credit growth) can be assessed by using our various model variants. To illustrate the sluggish demand explanation, we fitrst focus on the incremental impact of allowing for corporate debt overhang. The panels in Figure ?? show how the model response depends on corporate debt overhang. They show the response of various variables for two model variants: one with debt overhang in banks only (slotted line) and one where corporate debt overhang is added in (solid line). Clearly the model with corporate debt overhang generates more of a recessionary response to a negative productivity shock. Such a shock increases the corporate default probability so that firms' profits become more likely to be seized by creditors. This possibility reduces 
Figure 2: Firm DO: Productivity shock of $-5 \%$
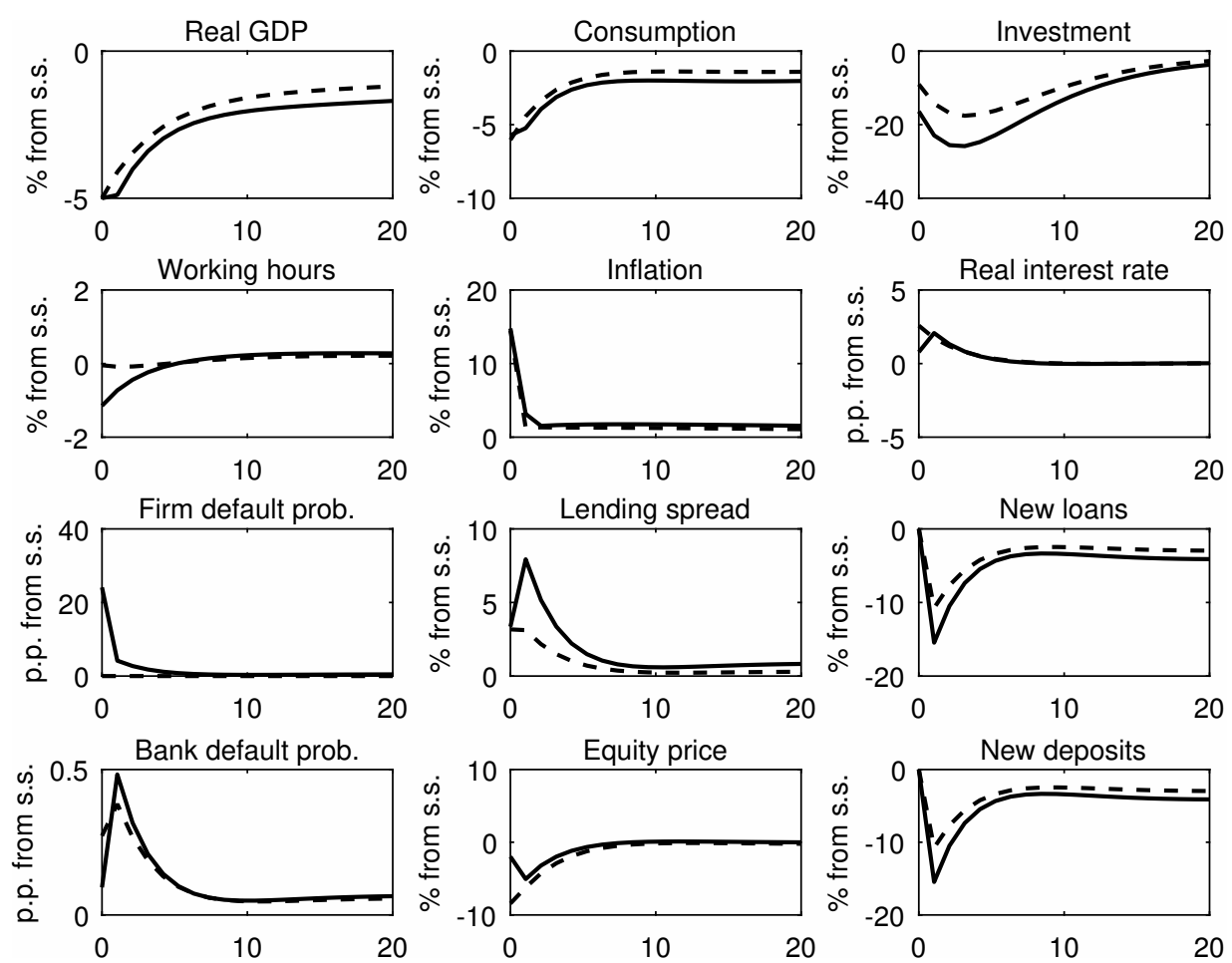

Note: Slotted line presents IRFs of the model with bank debt overhang but without corporate debt overhang. Solid line presents IRFs of the model with both bank debt overhang and corporate debt overhang.

a firm's expected (private) benefits from investing and as a consequence firms buy less physical capital and hire less workers. The panels presented below show the IRFs to a productivity shock of $-5 \%$.

The negative productivity shock makes firms less efficient and this raises marginal production costs which is a cost push factor temporarily pushing up inflation. Equally lower output given demand is another upward factor. The policy rate responds to higher inflation and given the parametrization of the Taylor rule, real interest rates increase. However, in the debt overhang variant investment response is more restrained which weighs on aggregate demand; this creates an offsetting effect on real interest rates so with corporate debt overhang the real interest rate increase by less. There is not much of a spillover effect of corporate debt overhang to bank debt overhang. This is partially related to the model structure: since banks live for two periods only, realized returns on loans do not affect bank performance or their funding costs further out in the future. Bank default probabilities barely edge up in response to higher corporate debt overhang. However, banks do respond to higher corporate default probabilities by lending less so the lending spread is higher (the lending spread is measured as a difference between expected real returns on new loans and the expected real deposit rate). 
Figure 3: Bank DO: Productivity shock of $-5 \%$
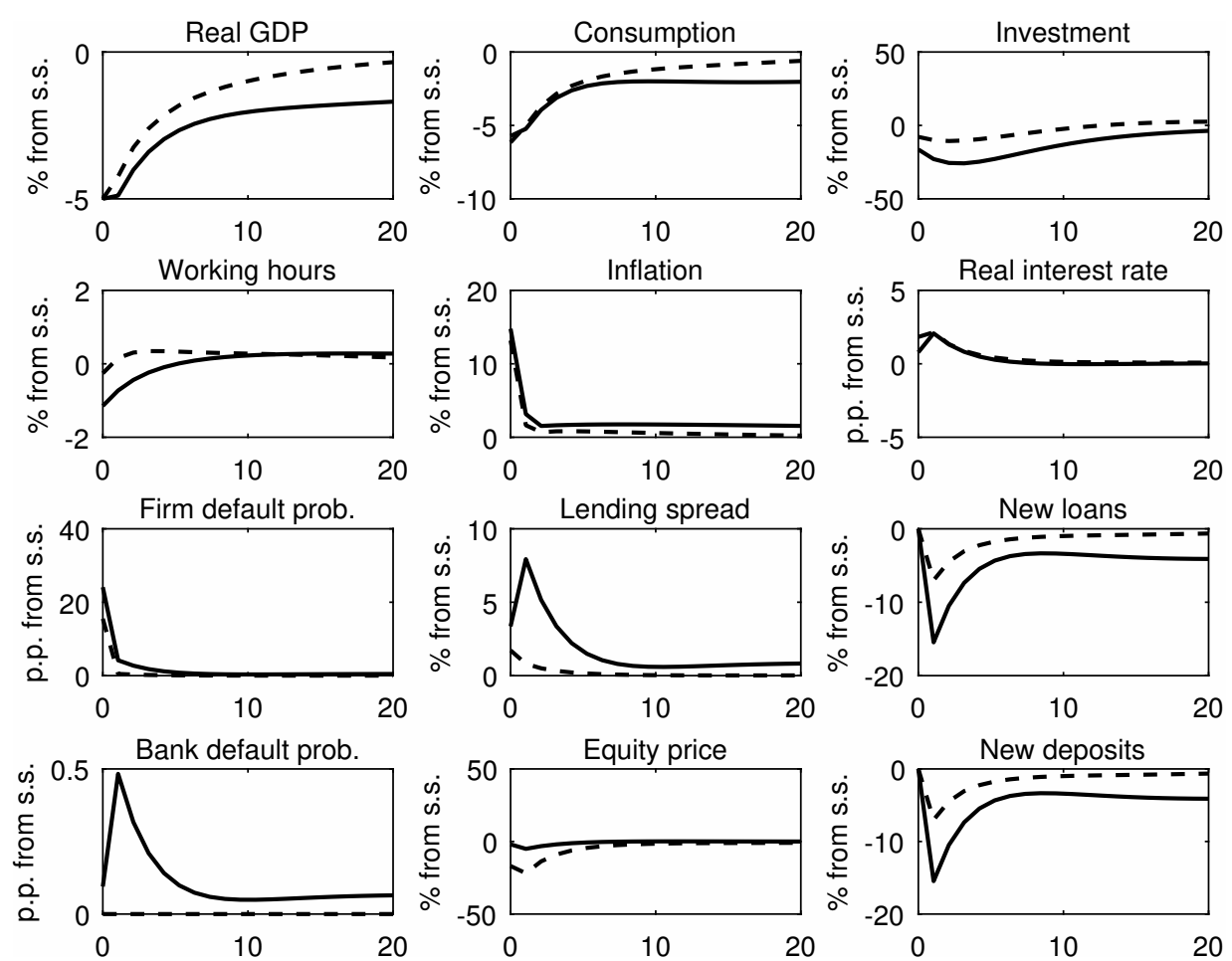

Note: Slotted line presents IRFs of the model with corporate debt overhang but without bank debt overhang. Solid line presents IRFs of the model with both bank debt overhang and corporate debt overhang.

Next, we explore debt overhang in banks as a factor explaining low credit growth. We once again model a low productivity shock and compare the model responses using a model variant with corporate debt overhang only and a model variant where both banks and firms are subject to debt overhang, thereby highlighting the incremental impact of debt overhang in banks. Figure ?? plots responses of both model variants.

The presence of debt overhang in banks gives rise to an additional wedge factor. In the presence of bank debt overhang, the banks' default probability goes up as loan prospects deteriorate (solid line). Credit supply istherefore significantly lower in the bank debt overhang variant, and interest rate spreads are correspondingly higher. As a consequence the default probability of firms goes up more also in the bank debt overhang case as the credit squeeze takes its toll. More expensive corporate credit in turn reduces demand for working capital and negatively affects production.

Finally we can also analyze the impact of debt overhang not by using two different model variants but by using one only but subjecting it to different shocks. We use the baseline model with debt overhang in both corporate and banking sector, and in one set of runs hit the model just with a negative productivity 
Figure 4: Productivity shock of $-5 \%$ and old loans return shock of -5 p.p.
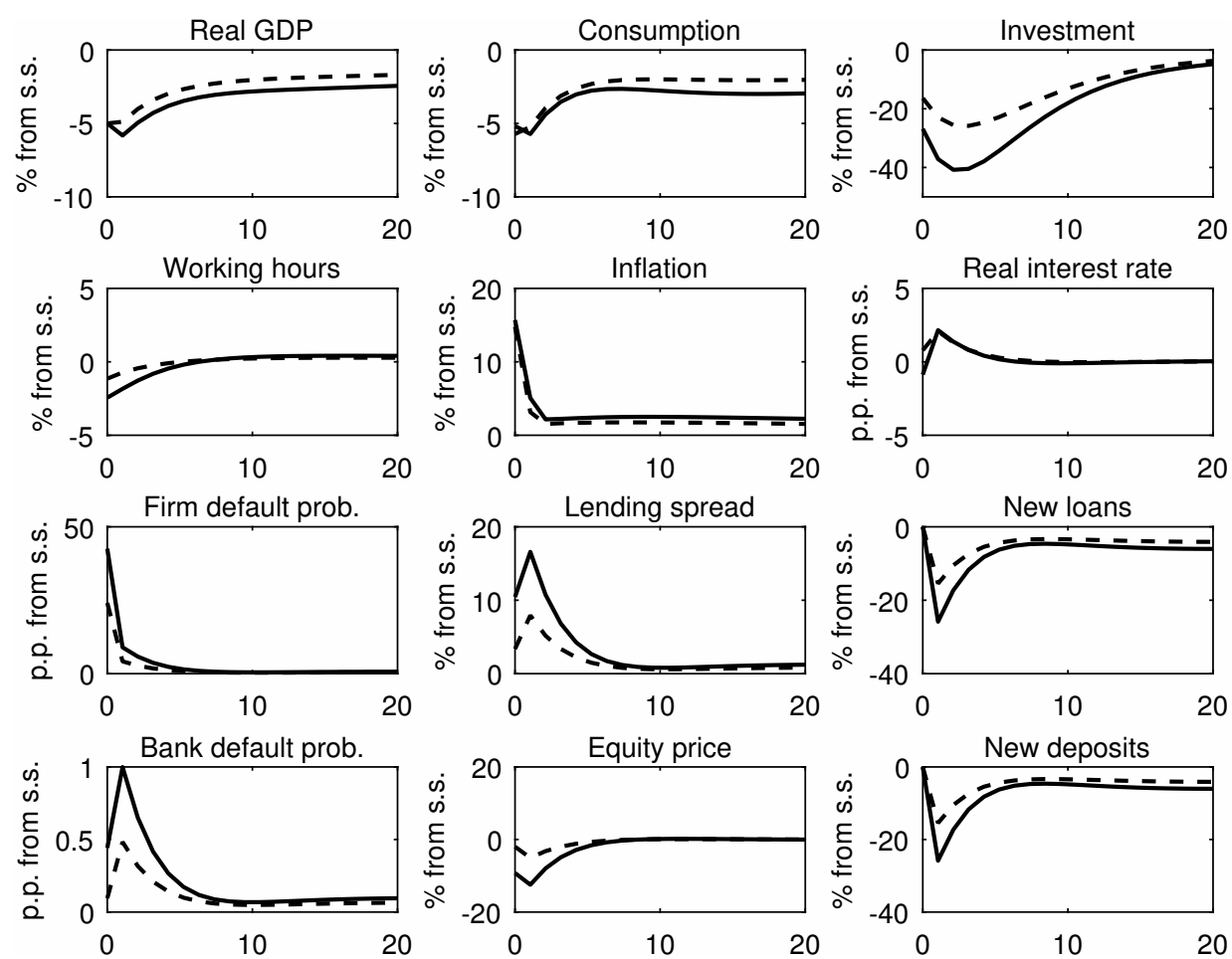

Note: Both cases present IRFs of the model with bank debt overhang and corporate debt overhang. Slotted line plots IRFs to a negative productivity shock. Solid line plots IRFs to a negative return shock to old loans correlated with a negative productivity shock.

shock (slotted line). The second set of IRFs gives the model responses to again the negative productivity shock but now accompanied by a negative return shock to old loans on bank balance sheets (solid lines). An unexpected decline in returns on old loans triggers bank debt overhang so the difference between the model responses is driven by increased debt overhang in banks.

Figure ?? plots the various model responses. Differential responses from the same model to a productivity decline with and without an additional bank debt overhang shock are similar to the differential response of the two model variants with and without dominant bank debt overhang given in Figure ?? The additional bank debt overhang shock makes real variables drop by more, because of the higher bank default probability. Higher bank default probability creates those aggregate losses by discouraging banks form lending so new loans decline by more. Similar to what we saw in Figure ??, bank debt overhang has strong spillovers to the corporate sector. Lower lending reduces not only aggregate production but also firms' chances to survive. The additional bank debt overhang shock also doubles an increase in the corporate default probability. 


\section{Average Implied Volatility Eurozone STOXX50 24 months to maturity options}

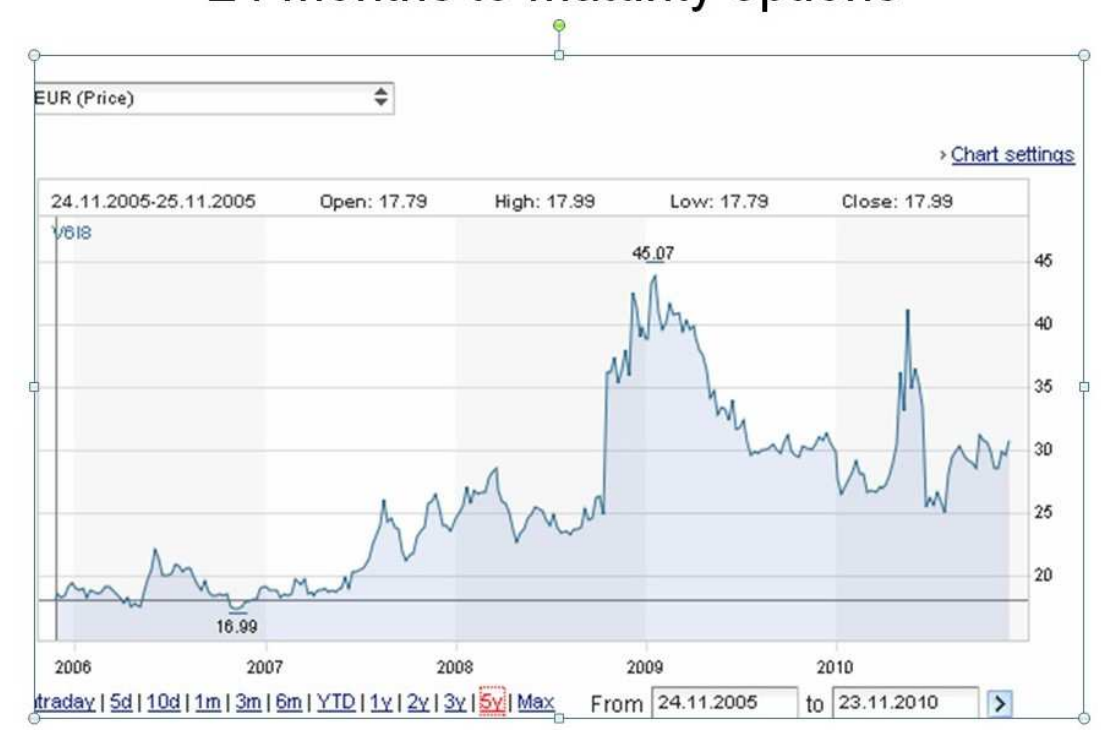

Figure 5: Expected volatility (VSTOXX, 24 month to maturity options)

\subsection{Volatility shocks}

Next we analyse volatility shocks under different frictions, obviously a very relevant experiment against the backdrop of the GFC, since the onset of of that crisis was characterized by a huge jump in expected and actual volatility. Figure 5 below shows that the market perception of long run (24 months) volatility almost doubled at the onset of the internationalization of the GFC, the day of the Lehman bankruptcy. The figure shows the implied volatility derived from a basket of European options with 24 months to maturity, and can be interpreted as the market's view on volatility over the next two years. The VSTOXX indices derived from shorter maturities showed even larger jumps, We shock the model with a doubling of the (exogenous component of) volatility of corporate profits.

In the first panel in Figure ?? below we show the relevance of corporate debt overhang for the response to volatility shocks by comparing a model run with and without corporate debt overhang. Both cases are characterized by banking debt overhang. Not surprisingly, the increase in prospective corporate profit volatility has a negligible impact when bank debt overhang is the only problem: bank DO itself is influenced by shocks on old loans, not by volatility of new projects; but corporate debt overhang is much worsened when volatility increases. This becomes visible in spite of our first order solution methodology because volatility shows up in the first order conditions, in the option's Greeks. Note that in this set of runs we endogenize the volatility of corporate profits by using the iterative process sketched in subsection 
Figure 6: Firm DO: Volatility shock of $100 \%$
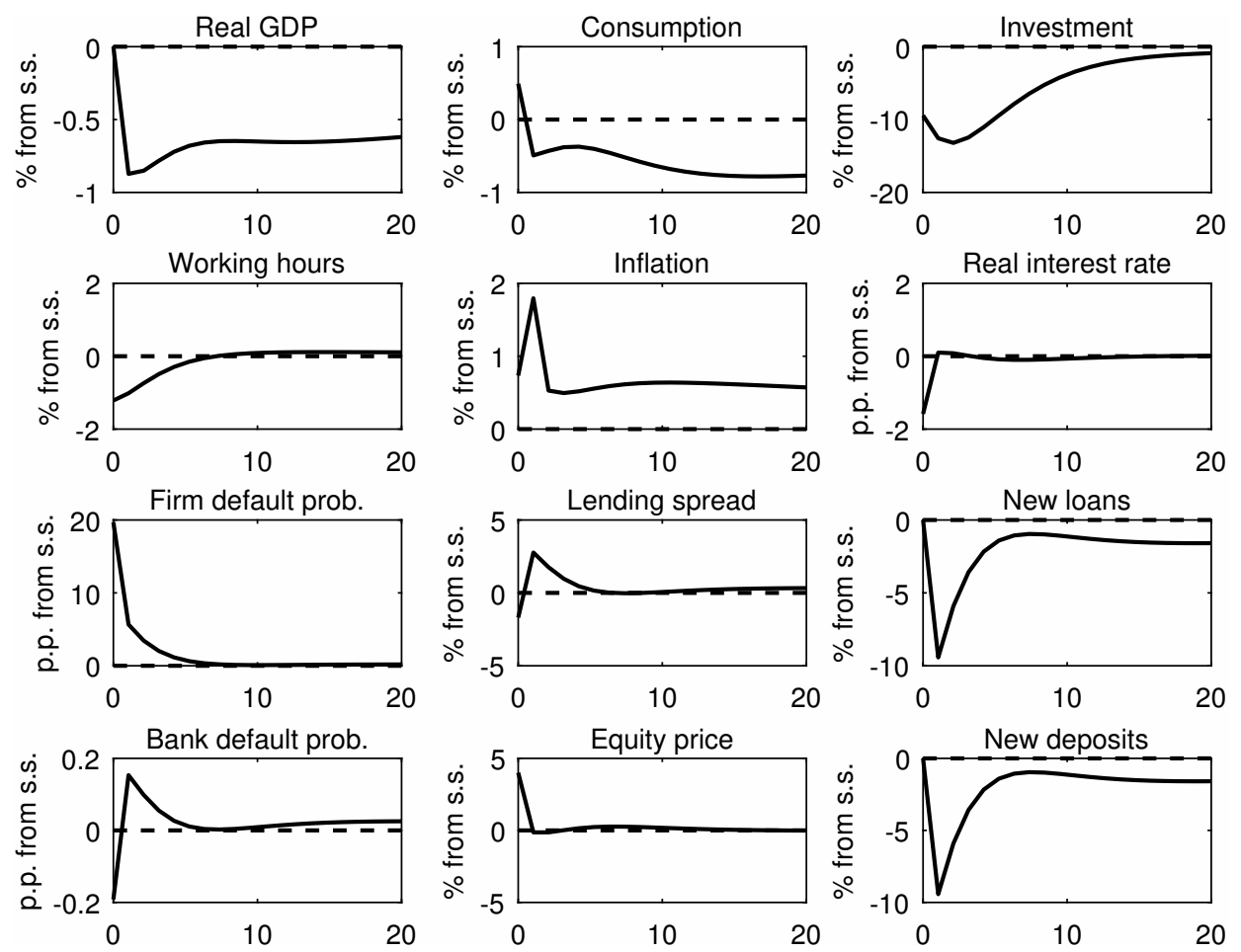

Note: Slotted line presents IRFs of the model with bank debt overhang but without corporate debt overhang. Solid line presents IRFs of the model with both bank debt overhang and corporate debt overhang.

2.7 .

Compared to the bank DO case only (the slotted line), volatility has a major and strongly negative impact on GDP: doubling the exogenous volatility component of corporate profits almost immediately leads to a full percentage drop in GDP and a substantial increase in corporate defaults which only slowly dies out over time as the shock subsides. Lending spreads go up in line with the rise in the default probability and investment goes down steeply; higher volatility leads to a sharp increase in the moral hazard problem that is behind the macroeconomic importance of corporate debt overhang to begin with, the non-contractibility of investment and employment. Employment goes down steeply also although it recovers as real wages adjust.

\subsection{Alternative explanations for reduced credit supply and the ma- croeconomic impact of higher capital requirements}

Consider next the impact of higher capital requirements banks were required to meet in both the US and the Eurozone. A key issue is how these higher requirements are met, through new equity issues like 
in the US or through asset substitution like in Europe. In the first case, one expects higher requirements will go together with an expanding balance sheet and increased loan supply; in the second case banks are reallocating assets away from risk weighted corporate loans to zero risk weight assets like sovereign debt and the supply of loans will actually go down as banks meet higher capital requirements through what is called asset substitution. One of us has discussed these mechanisms extensively elsewhere focusing on the impact of differential capital requirements for corporate loans and soveriegn debt and the asset substitution that differential gives rise to (van der Kwaak and van Wijnbergen (2017)). Here we want to focus on a different issue, also highlighted in the partial equilibrium analysis of Bahaj and Malherbe (2016): when risk shifting is the dominant factor in bank frictions (because of the interaction of low capitalization with limited liability), banks will respond differently to higher capital requirements than when debt overhang is the dominant friction. We sketch the differential macroeconomic responses in the two cases in this section.

We first use the model variant with risky new lending, to highlight risk shifting as a mechanism. In modeling this mechanism we follow the approach taken by Bahaj and Malherbe (2016). Returns on new loans are subject to idiosyncratic bank portfolio quality shocks which, in addition to aggregate shocks, also affect bank survival probabilities. To eliminate debt overhang from this model variant, we assume old loans on balance sheets to be risk free, thereby shutting down the debt overhang channel for banks. Figure ?? plots model responses to a doubling of capital requirements, pretty much what happened in Europe after the Lehman crisis and the introduction of Basel III. This was initially to be phased in over 2012-2019 but implementation was accelerated by the ECB's requirement that banks if they wanted to be admitted in the SSM (Single Supervisory Mechanism) at its inception date of September 2014, they would have to fully comply with the BIII capital requirements by that date. This shift represented an increase of T1 (and Additional T1 or AT1) capital requirements of 50\%, going up from 4 to 6 percentage points of Risk Weighter Assets (RWA). However BIII also tightened up capital quality requirements and introduced more stringent methods for calculating VARs (Values At Risk) and the derived Risk Weights, so we represent these shocks by a doubling of the required capital ratio $\gamma$. And we compare the model response under risk shifting as dominant friction with the response in the model variant with debt overhang as the dominant friction.

Figure ?? shows that doubling capital requirements is severely recessionary if risk shifting in response to low capitalization and limited liability is the dominant friction, i.e. new loans are risky but old loans are risk-free. A doubling of capital requirements then leads to a marked decline in GDP, lower investment and, obviously, in response also a drop in consumption. However when capital requirements are raised from a starting position where debt overhang is the dominant friction, the exact opposite happens: GDP growth accelerates and investment and consumption pick up rather than fall. One should note that these 
Figure 7: Leverage shock of $100 \%$
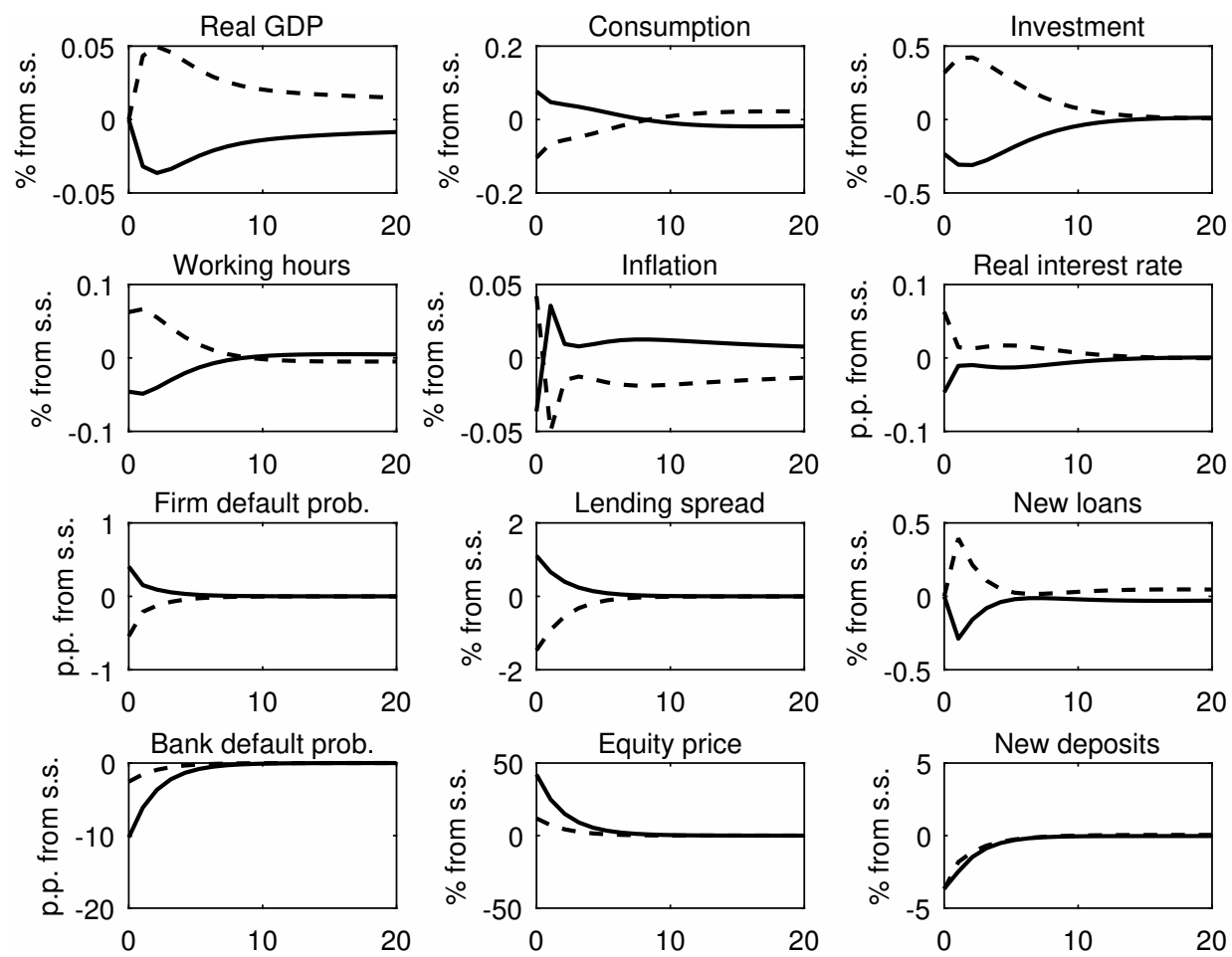

Note: Slotted line plots IRFs of the model with bank debt overhang. Solid line plots IRFs of the model with bank risk shifting. In both cases financially constrained firms are subject to debt overhang. 
macro responses are radically different but welfare assessments most likely are not: the higher capital requirements reduce debt overhang which leads to less rejection of positive NPV projects which is good in terms of welfare, but in the case of risk shifting, loans go down because risk is more adequately priced in now that limited liability has a smaller impact which is also good in welfare terms. The decline in loans represents less approval of negative NPV projects with excessive risk which previously were only approved because the downside risk was shifted to creditors.

The sharp discrepancy between the two cases is in line with the partial equilibrium analysis in Bahaj and Malherbe (2016). In the risk shifting case, higher leverage requirements make banks internalize negative returns of new projects; banks cut lending because their expected returns become lower once downside risk is also taken into account. When banks face debt overhang, higher capital requirements also make banks' private incentives more aligned with the social optimum which explains why in both cases welfare most likely goes up although the loan response and all macro indicators go in opposite directions. Since higher capital requirements decrease banks' default probability, banks then internalize more of the left tail of the returns distribution and cut lending accordingly. But with more capital less of the returns on new loans will be appropriated by old creditors and so lending goes up in that scenario. And higher credit supply boosts economic activity. So although the leverage shock decreases bank default probability in both models, this generates opposite impulse responses due to the differential impact on bank incentives. This analysis may shed light on why one should expect a cleaning up of Italian banks' bad loans and forcing through an increase in capital will most likely lead to a recovery of bank credit and positive macro impulses although the strengthening of capital in the Northern European countries has in fact been accompanied by persistently sluggish credit growth if not actually by continued decline in credit to the corporate sector.

The final experiment in this section compares the impact of imposing higher capital requirements in an environment with bank debt overhang and an environment where corporate debt overhang is present also (Figure ??). The slotted line in Figure ?? describes the shock in a model variant with corporate debt overhang only, and the solid line represents the model with both debt overhang and bank debt overhang.

The way to read this plot is to first look at the slotted line: it shows that forcing higher capitalization does very little good as long as a substantial corporate debt overhang persists also. The solid line adds bank debt overhang to the set of pre-existing wedges and very clearly shows a substantial and positive impact: thus if Bank Debt Overhang is a major problem, forcing recapitalization does help substantially even when there also is corporate debt overhang: the impact then becomes substantial and positive, as witnessed by the GDP response where the slotted line barely moves but the solid line shows a substantial positive response. The model runs highlight why the US recaps where so successful, they focused on 
Figure 8: Leverage shock of $100 \%$
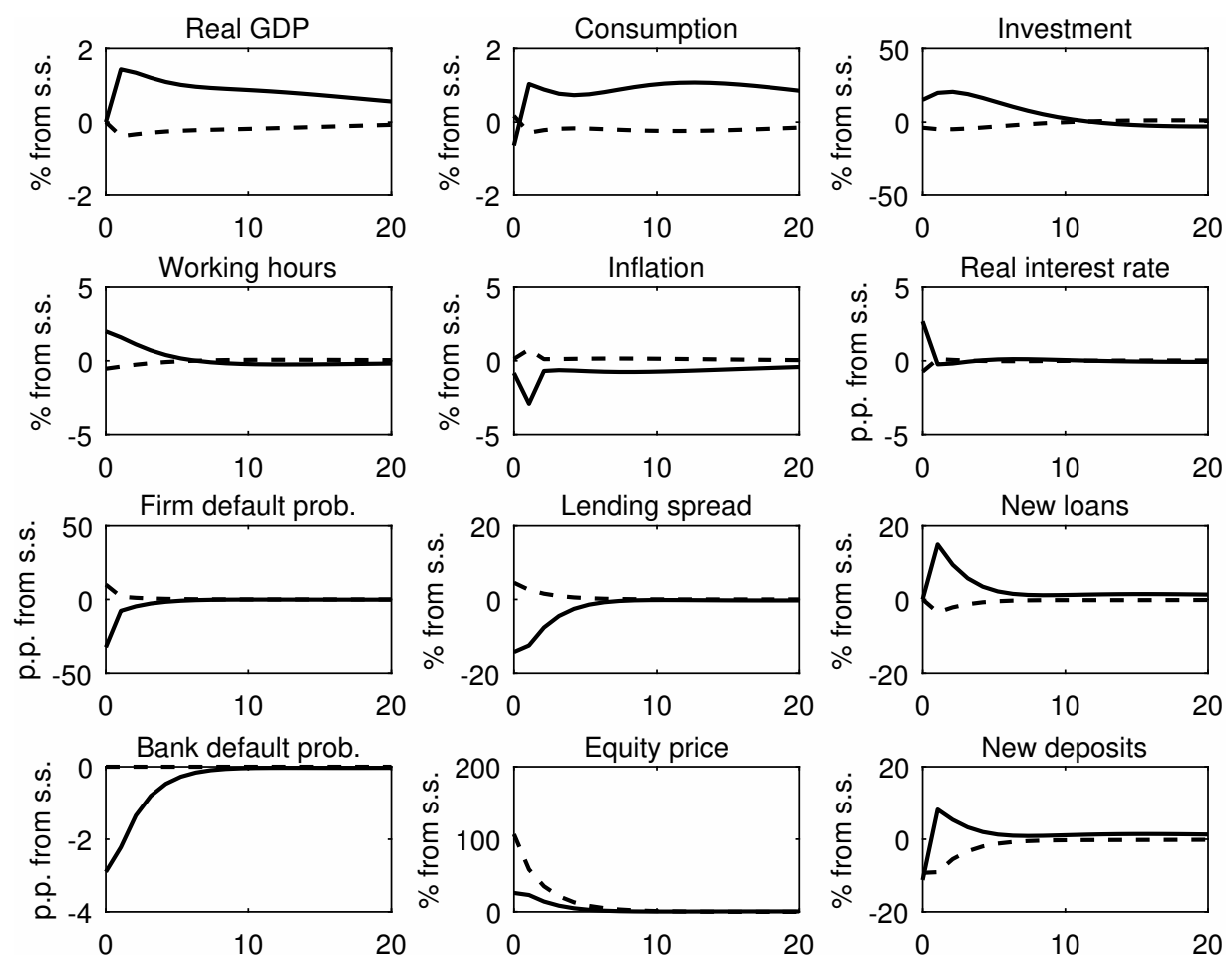

Note: Slotted line plots IRFs of the model without bank debt overhang. Solid line plots IRFs of the model with bank DO. In both cases financially constrained firms are subject to debt overhang. 
what apparently was the major problem, debt overhang in banks.

\subsection{Financial frictions and the effectiveness of fiscal policy}

In this section we investigate the interaction between the various financial frictions and fiscal policy.

Figure 9: Firm DO: Fiscal policy shock of $5 \%$
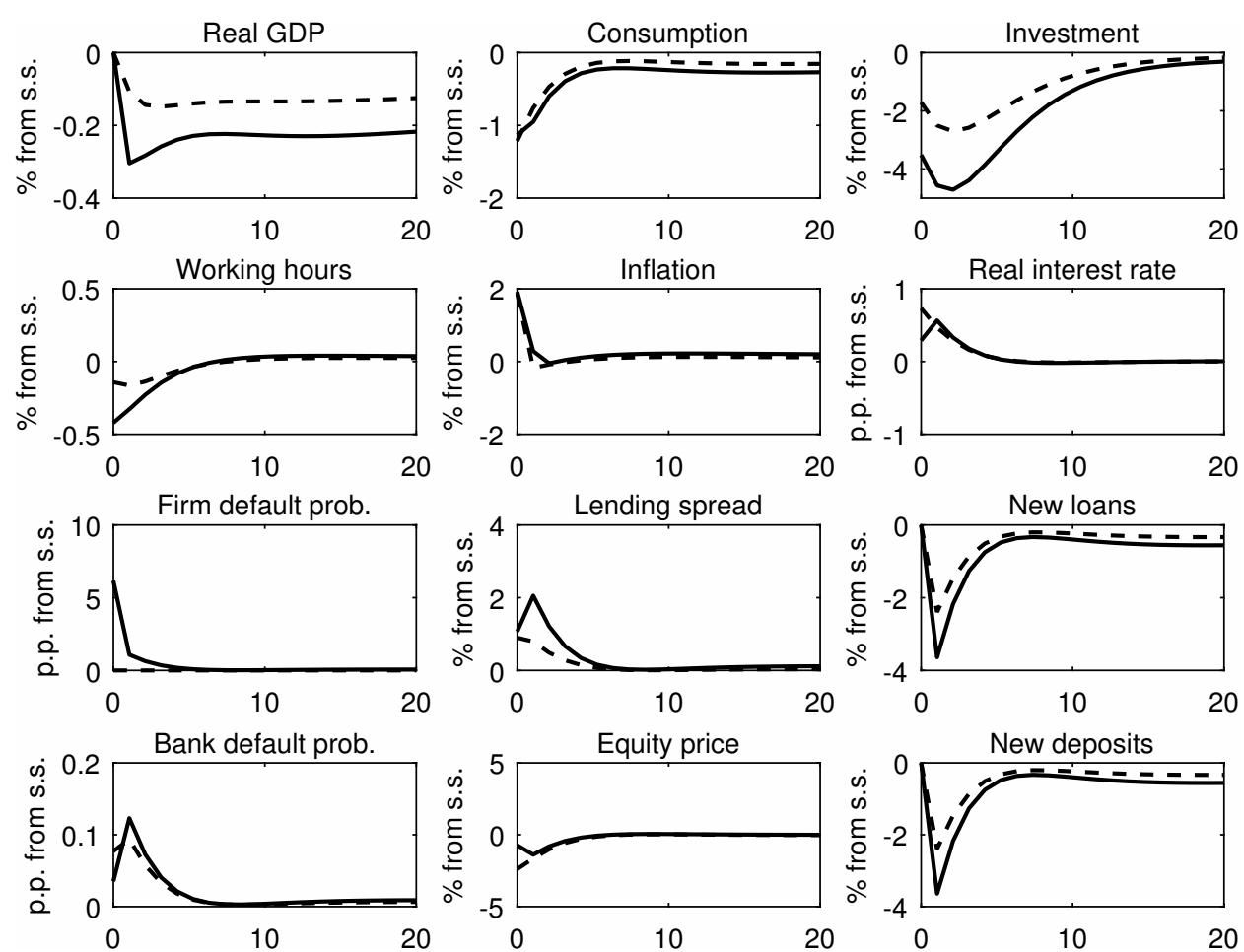

Note: The slotted line presents IRFs of the model with bank debt overhang but without corporate debt overhang. The solid line presents IRFs of the model with both bank debt overhang and corporate debt overhang.

Figure ?? shows the effects of a fiscal shock in a model with bank debt overhang and compares them with model responses from a variant where corporate debt overhang is also present. Introducing corporate debt overhang in addition to bank debt overhang clearly worsens the response to fiscal policy, making it much more contractionary. The completely negative GDP response to increased fiscal spending is related to the strong impact of the reduction in bank loan supply on aggregate output. Corporate debt overhang triggers higher expected defaults among firms in response to reduced loan supply and therefore higher credit spreads which in turn lead to further output losses. The negative multiplier effects are correspondingly stronger in the dominant corporate debt overhang case. The reader should note that in the short run output is reduced by more restrictive credit conditions because in the model set up used here loans are needed to finance working capital (wage payments) and if these loans are not forthcoming, 
increases in labor cannot be accommodated. This crowding out through reduced availability of working capital completely eliminates the first round positive impact that traditionally occurs in this type of NK DSGE models in response to higher fiscal spending. van der Kwaak and van Wijnbergen (2017) also find a negative impact of banking frictions on fiscal multipliers (although the frictions they analyse are different from the frictions considered here) but in their modeling framework loans are only used for investment purposes, which allows for a more traditional initially positive output response. Assuming complete dependence of current output on the availability of working capital may exaggerate the negative macro aspects of crowding out through financial ftrictions; on the other hand in particular smaller firms do depend on bank credit even for such short term financing needs, so this may be an important new channel to consider.

Figure ?? evaluates the effect of expansionary fiscal policy focusing on the incremental impact of bank debt overhang by comparing a model variant with only corporate debt overhang (the slotted line in ??) with output from a model variant where bank debt overhang is introduced in addition to corporate debt overhang (the solid line in ??). Bank debt overhang is shown to reduce the effectiveness of fiscal policy too, very similar to what happens with only corporate debt overhang although the channels of crowding out differ somewhat. A key difference is that bank default probabilities do not increase in the absence of bank debt overhang, which makes for a less negative investment response and a more rapid phasing out of the negative GDP response (cf the slotted lines in ??).

The impact of flexibility in labor demand.

So far we assumed that not just investment expenditure is debt financed, as in most financial friction models, but also working capital and in particular wage payments. This is much closer to reality for small and medium firms than for large corporations (Chodorow-Reich (2013)). That implies that labor used in production of homogeneous goods for the period in which the shock hits is set before they actually do. This assumption obviously has major implications for in particular the output response to fiscal policy shocks. By eliminating the positive impact effect it actually turns fiscal multipliers negative. We relax this assumption below and in fact look at the other extreme, where labor demand can actually be adjusted in the period the shock hits. This should be closer to reality for large firms (again see Chodorow-Reich (2013)). On an aggregate macroeconomic level one should expect results in between these two extremes: smaller multipliers with frictions, possibly turning negative if coverage of the frictions is sufficiently wide. We only present the bank debt overhang case here since the relative impact of policy responses over different scenarios as to which friction is dominant is similar to the rigid short term labor use case. Figure ?? shows the IRFs, again in response to a fiscal policy shock.

We now see labor use go up on impact, and as a consequence a positive impact on GDP initially. Without banking frictions the multiplier effect gradually dies out to zero, but with debt overhang we 
Figure 10: Bank DO: Fiscal policy shock of $5 \%$
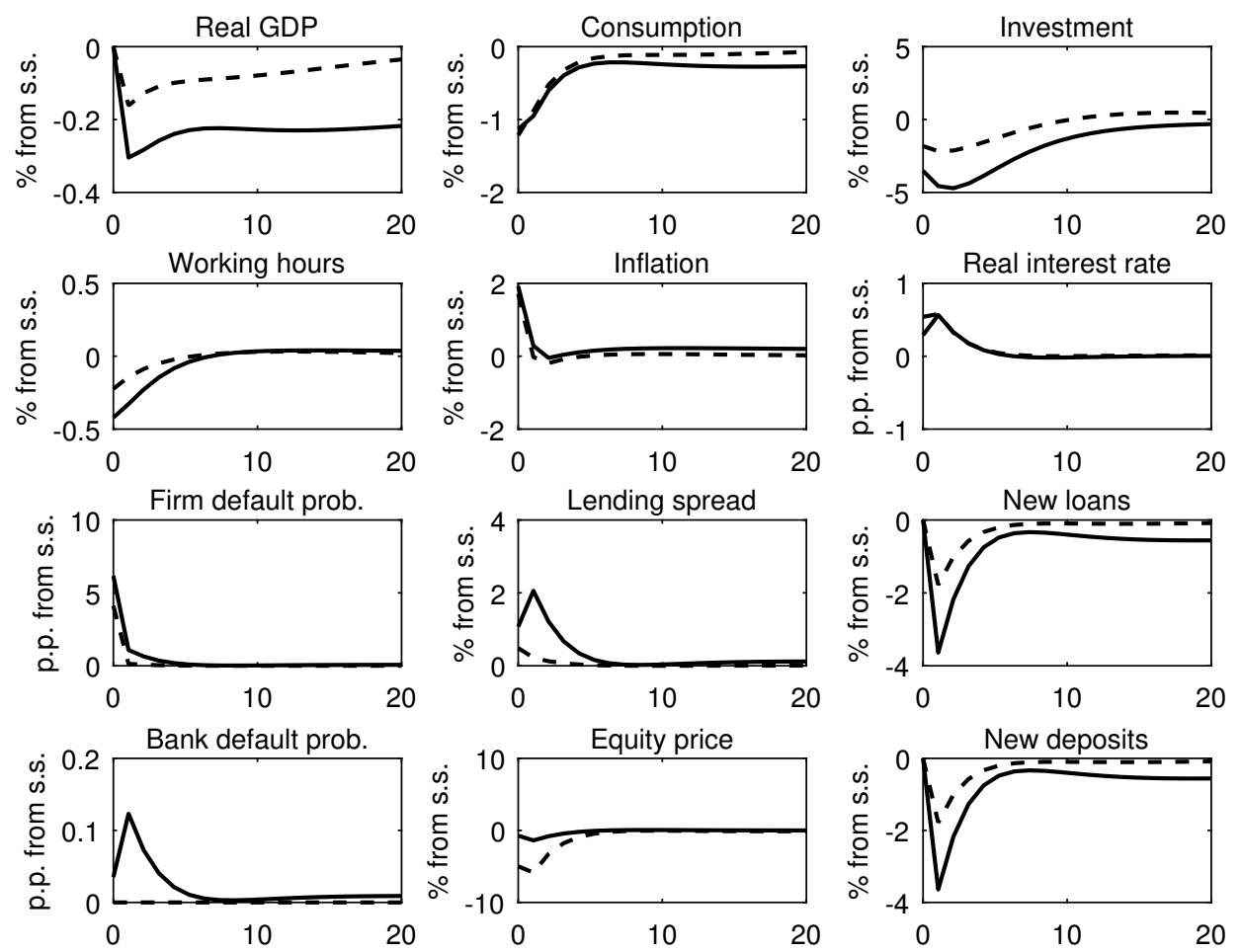

Note: The slotted line presents IRFs of the model with corporate debt overhang but without bank debt overhang. The solid line presents IRFs of the model with both bank debt overhang and corporate debt overhang.

should expect a period of negative output response following the initial positive impact. Consumption and investment fall straight away however, and much more so under bank debt overhang as private expenditure is crowded out by public expenditure. The mechanism is clear enough: lending spreads go up as loan demand and loan supply get out of balance; new loans actually decline, and much more so under bank debt overhang. The higher lending costs lead to higher corporate defaults and subsequently also to higher defaults in the banking system, all of which much more so in the debt overhang scenario.

\subsection{Financial frictions and the effectiveness of monetary policy}

Finally we show the impact of monetary policy under various financial frictions. We show only one of the plot sets for the simple reason that all of them show the same pattern: the impact of expansionary monetary policy is amplified by financial frictions (Figure ??). Basically, all frictions are one way or another related to the burden of debt, and that burden becomes less with lower interest rates, so that secondary effect mitigating the negative impact of financial friction works as an amplification mechanism. We show the plots for the case of dominant corporate debt overhang below, and the others are left to 
Figure 11: Bank DO: Fiscal policy shock of $5 \%$ with flexible labor demand
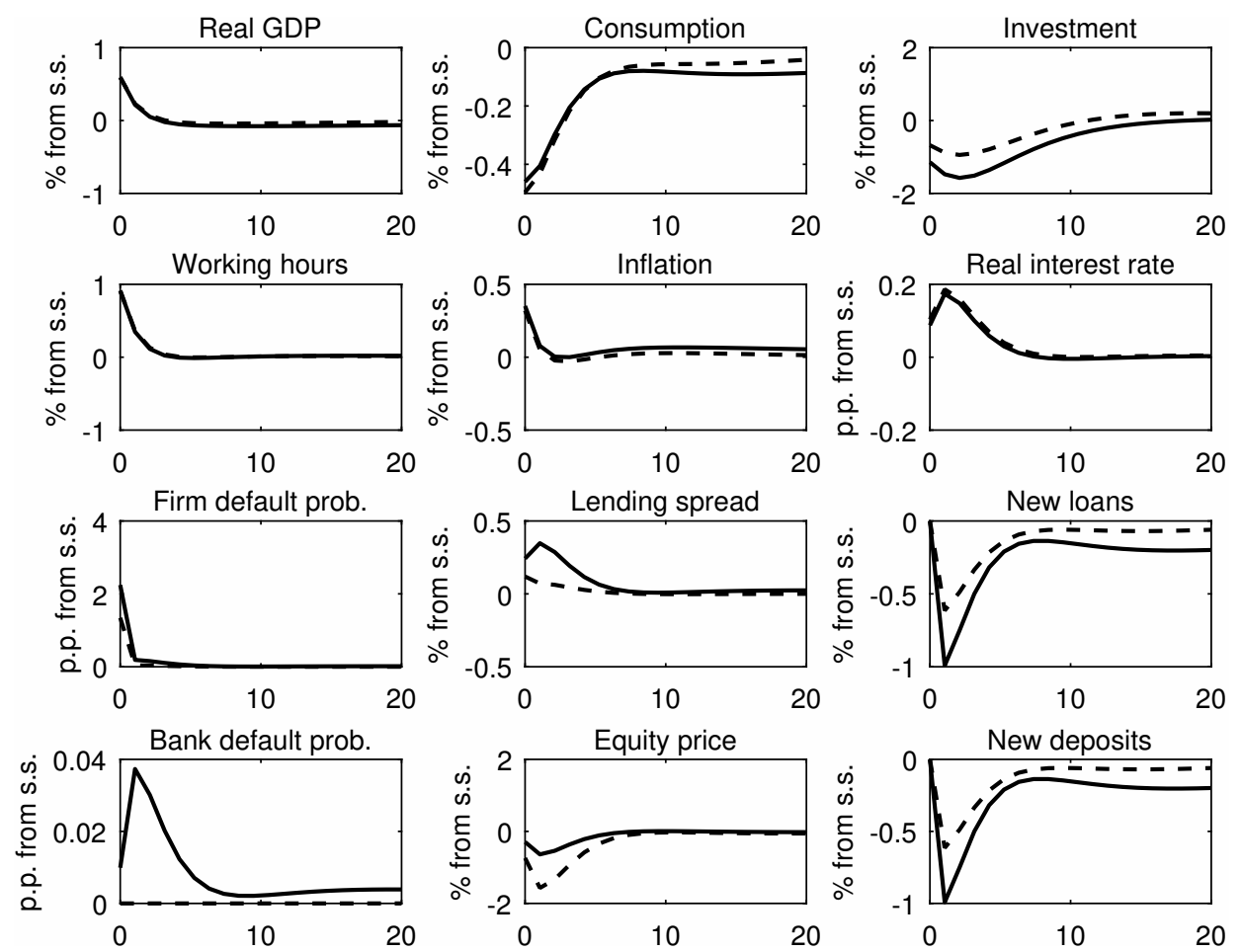

Note: Slotted line presents IRFs of the model with corporate debt overhang but without bank debt overhang. Solid line presents IRFs of the model with both bank debt overhang and corporate debt overhang. We assume flexible labor demand.

the appendix.

We should point out that we follow the current DSGE literature in modeling monetary policy in a highly counterfactual and unrealistic way: like the entire DSGE literature, monetary policy is implemented as if central banks manipulated bank deposit rates following a Taylor rule. In a companion paper we explore the consequences of a more explicit modeling of the interactions between central banks and commercial banks.

\section{Conclusions}

We started out by drawing attention to the fact that the post-Lehman Great Financial Crisis (GFC) was characterized by a wide variety of macroeconomic responses to seemingly similar policy measures. The main question we raise based on that experience is whether different frictions being dominant in different countries can explain different macro responses to similar policy measures. To answer that question, we have explored the consequences of different financial frictions on the corporate and banking 
Figure 12: Firm DO: Monetary policy shock of -5 p.p.
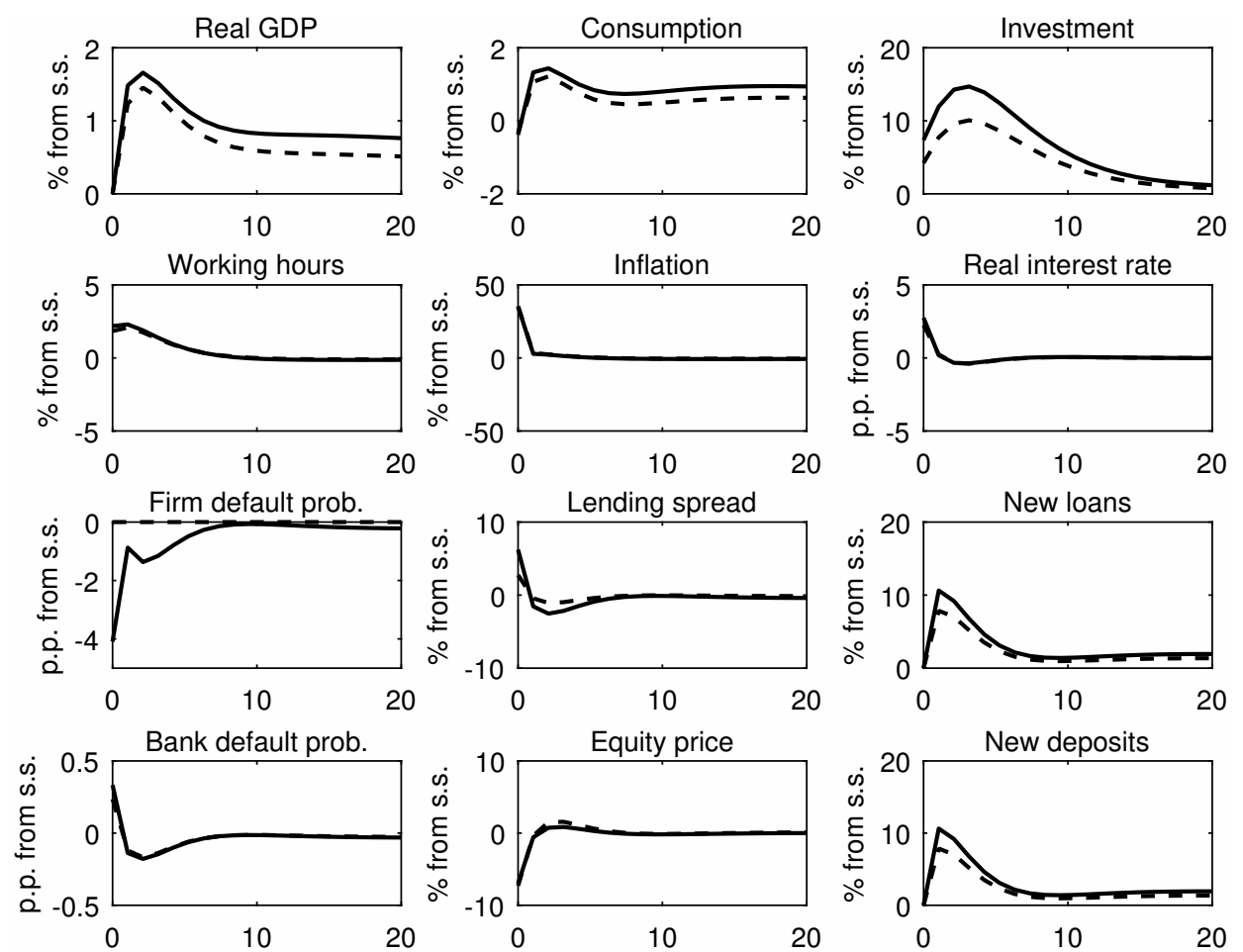

Note: Slotted line presents IRFs of the model with bank debt overhang but without corporate debt overhang. Solid line presents IRFs of the model with both bank debt overhang and corporate debt overhang.

level for macroeconomic policy responses. We introduce a variety of financial frictions in an otherwise standard NK DSGE model. In particular we build on Merton's credit risk model (Merton (1974)) and introduce incomplete contractibility in investment and labor hiring decisions and the ensuing possibility of debt overhang on the corporate level; and introduce debt overhang within banks in addition to risk shifting behavior, also in banks, in response to low capitalization combined with limited liability.

We then ask whether and how recession responses (to a negative productivity shock) depend on which of these frictions is dominant by comparing model variants with and without the particular friction at issue. We demonstrate that higher corporate debt overhang leads to more negative macroresponses (higher inflation and lower output growth) after a negative productivity shock, as does debt overhang in the banking sector, than in the case where the only friction is risk shifting in banks due to low capitalization in combination with limited liability. A similar issue comes up with volatility shocks: they give rise to strongly negative macro responses when corporate debt overhang is an important friction. Higher volatility increases the value of the embedded options giving rise to corporate debt overhang, and worsens the moral hazard problem they give rise to: Corporate Debt overhang is a problem because of 
the non-contractibility of investment and employment and indeed investment and employment are cut back severely leading to an immediate and persistent drop in GDP.

We then look at policy responses to an emerging crisis. First we show that the macroeconomic response to higher capital requirements is very different depending on which particular friction dominates. When there is debt overhang in banks, higher capital requirements leads to more, not less loan supply, and consequently to lower credit spreads and positive macroeconomic responses: imposing higher capital requirements is expansionary in a (banking) debt overhang situation. But it leads to lower loan volumes when excessive risk shifting is the dominant problem in banks: higher capital requirements lead to a decline in lending after banks increase their equity ratio and subsequently display less risk shifting behavior, although that decline in loan volumes may actually be socially optimal, there was too much risk taking before the higher capital requirements were imposed. And recapitalizing banks does not in fact have much of an impact if corporate debt overhang is the dominant friction..

Finally we analyze the effectiveness of fiscal stimulus programs under different financial frictions. We show that fiscal spending is less expansionary when debt overhang occurs, independently of whether the debt overhang is in the corporate or in the banking sector. Either way debt overhang greatly increases crowding out to the extent that multipliers actually become negative: fiscal expansion becomes contractionary. This effect is mitigated when bank credit only finances investment, in that case there is a positive impact on current output but the negative impact on future output remains: the severity of the negative impact of banking frictions on macro outcomes is shown to depend on the extent to which firms finance current (wage) costs through bank borrowing in addition to requiring credit to finance investment. Extensive reliance on bank loans to finance working capital for current expenses magnifies the macroeconomic impact of banking frictions. This suggests that the issues raised in this paper are more important in Europe than in the US, and more important in both regions for SMEs than for large corporations since the latter have access to capital markets for their working capital needs.

All these results do shed light on the differences in policy responses highlighted in the introduction by tracing them to the differential importance of corporate versus banking debt overhang, which we in turn can trace back to the different approaches followed on each side of the Atlantic in response to the undercapitalization of the banks after the onset of the financial crisis. In the US, strong measures were taken early on to force banks to raise new capital, both in 2008 (through TARP) and in 2009 (through the SCAP program). This may well have almost eliminated debt overhang problems, which can explain why fiscal policy was in fact helped along by a rising volume of bank loans to business from 2009 onwards and why recovery came to the US so much earlier than to Europe. Finally we also explored reduced bank risk shifting as an alternative explanation for low credit growth. Risk shifting banks would cut lending in response to higher capital regulation but this could be socially optimal. 
Such a situation would suggest different policy implications than a higher decline in bank lending in a recession with bank debt overhang. This discussion is relevant for a comparison of Northern versus Southern European experiences; in the North bank capitalization was much improved, which should lead to less risk shifting and possibly sluggish credit growth, but not an unhealthy decline since it stems from banks incorporating risks more completely in their decision making. In the Southern periphery however, the major change in the banking sector involved an explosion of bad loans (and associated increase in NPLs). There debt overhang was more likely to be the main driver of sluggish credit growth and a strong effort directed at raising capital ratio's is likely to lead to more, not to less credit growth and should have substantial macroeconomic benefits. Model estimation on Eurozone data could evaluate the dominating financial friction in the banking and thus provide deeper insights into the situation of low credit growth in Europe. Finally we venture that the results sketched in this paper are very likely to shed light on the apparent failure of the ECB's policies to revive credit to the corporate sector, its LTRO and TLTRO programs. These policies consisted of extending more and cheaper credit to the banks, not obviously the right policy if a capital shortage is the dominant problem in either the corporate and/or the banking sector.An obvious take away for policy makers and their (quantitative) advisors is that paying attention to financial frictions and in particular to their "location", i.e. it matters between which parties the friction exists, is of essential importance for correct predictions of sometimes even the sign, let alone the magnitude, of the impact of a large array of commonly used policy measures.

\section{References}

Acharya, V. V., T. Eisert, C. Eufinger, And C. W. Hirsch (2016): "Real effects of the sovereign debt crisis in Europe: Evidence from syndicated loans," Unpublished manuscript.

Bahaj, S. And F. Malherbe (2016): "A Positive Analysis of Bank Behaviour under Capital Requirements," CEPR DP1160\%.

Bernanke, B. And M. Gertler (1989): "Agency costs, net worth, and business fluctuations," The American Economic Review, 14-31.

Bernanke, B. S., M. Gertler, and S. Gilchrist (1999): "The financial accelerator in a quantitative business cycle framework," Handbook of macroeconomics, 1, 1341-1393.

Brunnermeier, M. K., T. M. Eisenbach, and Y. Sannikov (2012): "Macroeconomics with financial frictions: A survey," NBER Working Paper No. 18102.

Chodorow-Reich, G. (2013): "The employment effects of credit market disruptions: Firm-level evidence from the 2008-9 financial crisis," The Quarterly Journal of Economics, 129, 1-59. 
Clerc, L., A. Derviz, C. Mendicino, S. Moyen, K. Nikolov, L. Stracca, J. Suarez, and A. VardoulaKIS (2011): "Capital regulation in a macroeconomic model with three layers of default," International Journal of Central Banking, 11, 9-63.

Hanson, S. G., A. K. Kasyap, And J. C. Stein (2011): "A Macroprudential Approach to Financial Regulation," Journal of Economic Perspectives, 25, 3-28.

Jakucionyte, E. And S. J. van Wijnbergen (2017): "Debt overhang and the macroeconmics of carry trade," Tinbergen Institute Discussion Paper 2017-005/VI.

Kiyotaki, N. And J. Moore (1997): "Credit cycles," Journal of Political Economy, 105, $211-248$.

McGowan, M. A., D. Andrews, and V. Millot (2017): "The walking dead?: Zombie firms and productivity performance in OECD countries," OECD Working paper.

Merton, R. C. (1974): "On the pricing of corporate debt: The risk structure of interest rates," The Journal of Finance, 29, 449-470.

Myers, S. C. (1977): "Determinants of corporate borrowing," Journal of Financial Economics, 5, $147-175$.

OCChino, F. (2017a): "The 2012 Eurozone Crisis and the ECB's OMT Program: A Debt-Overhang Banking and Sovereign Crisis Interpretation," European Economic Review.

- (2017b): "Debt-overhang banking crises: Detecting and preventing systemic risk," Journal of Financial Stability, 30, 192-208.

Occhino, F. And A. Pescatori (2015): "Debt overhang in a business cycle model," European Economic Review, 73, 58-84.

VAn Der KwaAk, C. G. and S. J. van WiJnbergen (2017): "On the Macroeconomics of Bank Capital Regulation," CEPR DP12394. 


\section{Appendix}

\section{A: Derivation of the default probability}

We need to compute the expected value of the firm's payment function (we abstract from indices $i$ for the sake of brevity):

$$
E_{t} \min \left\{R_{t}^{R} \frac{l_{t}}{\pi_{t+1}}, \quad \kappa\left(p_{t+1}^{R} y_{t+1}^{R}+q_{t+1}(1-\delta) k_{t}\right)\right\}
$$

Define $\bar{y}_{t+1} \equiv \kappa\left(p_{t+1}^{R} y_{t+1}^{R}+q_{t+1}(1-\delta) k_{t}\right)$, where

$$
\bar{y}_{t+1} \sim \log \text {-normal }\left(\mu_{\bar{y}_{t+1}}, \sigma_{R}^{2}\right)
$$

Then the modified minimum function can be re-written as

$$
E_{t} \min \left\{R_{t}^{R} l_{t}, \quad \bar{y}_{t+1}\right\}
$$

Further

$$
\begin{aligned}
& E_{t} \min \left\{R_{t}^{R} l_{t}, \quad \bar{y}_{t+1}\right\}=R_{t}^{R} l_{t} \operatorname{Pr}\left(R_{t}^{R} l_{t}<\bar{y}_{t+1}\right)+\left(1-\operatorname{Pr}\left(R_{t}^{R} l_{t}<\bar{y}_{t+1}\right)\right) E_{t}\left(\bar{y}_{t+1} \mid \bar{y}_{t+1}<R_{t}^{R} l_{t}\right) \\
& =R_{t}^{R} l_{t} \operatorname{Pr}\left(R_{t}^{R} l_{t}<\bar{y}_{t+1}\right)+\left(1-\operatorname{Pr}\left(R_{t}^{R} l_{t}<\bar{y}_{t+1}\right)\right) \int_{0}^{R_{t}^{R} l_{t}} \frac{\bar{y}_{t+1} d F\left(\bar{y}_{t+1}\right)}{1-\operatorname{Pr}\left(R_{t}^{R} l_{t}<\bar{y}_{t+1}\right)} \\
& =R_{t}^{R} l_{t} \operatorname{Pr}\left(R_{t}^{R} l_{t}<\bar{y}_{t+1}\right)+\int_{0}^{R_{t}^{R} l_{t}} \bar{y}_{t+1} d F\left(\bar{y}_{t+1}\right) \\
& =R_{t}^{R} l_{t} \int_{R_{t}^{R} l_{t}}^{\infty} d F\left(\bar{y}_{t+1}\right)+\int_{0}^{R_{t}^{R} l_{t}} \bar{y}_{t+1} d F\left(\bar{y}_{t+1}\right) \\
& =R_{t}^{R} l_{t} \int_{R_{t}^{R} l_{t}}^{\infty} \frac{1}{\bar{y}_{t+1} \sigma_{R} \sqrt{2 \pi}} e^{\frac{-\left(\ln \left(\bar{y}_{t+1}\right)-\mu_{y}\right)^{2}}{2 \sigma_{R}^{2}}} d\left(\bar{y}_{t+1}\right) \\
& +\int_{0}^{R_{t}^{R} l_{t}} \frac{\bar{y}_{t+1}}{\bar{y}_{t+1} \sigma_{R} \sqrt{2 \pi}} e^{\frac{-\left(\ln \left(\bar{y}_{t+1}\right)-\mu_{y}\right)^{2}}{2 \sigma_{R}^{2}}} d\left(\bar{y}_{t+1}\right) \\
& =\left.R_{t}^{R} l_{t} \Phi\left(\frac{\ln \left(\bar{y}_{t+1}\right)-\mu_{y}}{\sigma_{R}}\right)\right|_{R_{t}^{R} l_{t}} ^{\infty}+\int_{0}^{R_{t}^{R} l_{t}} \frac{1}{\sigma_{R} \sqrt{2 \pi}} e^{\frac{-\left(\ln \left(\bar{y}_{t+1}\right)-\mu_{y}\right)^{2}}{2 \sigma_{R}^{2}}} d\left(\bar{y}_{t+1}\right) \\
& =R_{t}^{R} l_{t}\left(1-\Phi\left(\frac{\ln \left(R_{t}^{R} l_{t}\right)-\mu_{y}}{\sigma_{R}}\right)\right)-\left.\frac{1}{2} e^{\mu_{y}+\frac{\sigma_{R}^{2}}{2}} \operatorname{erf}\left(\frac{-\ln \left(\bar{y}_{t+1}\right)+\mu_{y}+\sigma_{R}^{2}}{\sqrt{2} \sigma_{R}}\right)\right|_{0} ^{R_{t}^{R} l_{t}} \\
& =R_{t}^{R} l_{t} \Phi\left(\frac{\mu_{y}-\ln \left(R_{t}^{R} l_{t}\right)}{\sigma_{R}}\right)+\frac{1}{2} E_{t}\left(\bar{y}_{t+1}\right)\left(\operatorname{erf}\left(\frac{\ln \left(R_{t}^{R} l_{t}\right)-\mu_{y}-\sigma_{R}^{2}}{\sqrt{2} \sigma_{R}}\right)+1\right) \\
& =R_{t}^{R} l_{t} \Phi\left(\frac{\mu_{y}-\ln \left(R_{t}^{R} l_{t}\right)}{\sigma_{R}}\right)+E_{t}\left(\bar{y}_{t+1}\right) \Phi\left(\frac{\ln \left(R_{t}^{R} l_{t}\right)-\mu_{y}-\sigma_{R}^{2}}{\sigma_{R}}\right) \\
& =R_{t}^{R} l_{t} \Phi\left(\frac{\mu_{y}-\ln \left(R_{t}^{R} l_{t}\right)}{\sigma_{R}}\right)+E_{t}\left(\bar{y}_{t+1}\right)\left(1-\Phi\left(\frac{\mu_{y}-\ln \left(R_{t}^{R} l_{t}\right)}{\sigma_{R}}+\sigma_{R}\right)\right)
\end{aligned}
$$


The expression can be simplified as

$$
E_{t} \min \left\{R_{t}^{R} l_{t}, \quad \bar{y}_{t+1}\right\}=\left(1-\Phi\left(d_{1, t}\right)\right) E_{t}\left(\bar{y}_{t+1}\right)+\Phi\left(d_{2, t}\right) R_{t}^{R} l_{t}
$$

where

$$
d_{2, t} \equiv \frac{\mu_{y}-\ln \left(R_{t}^{R} l_{t}\right)}{\sigma_{R}}, \quad d_{1, t} \equiv d_{2, t}+\sigma_{R}
$$

where

$$
\mu_{y} \equiv E_{t} \ln \left(\bar{y}_{t+1}\right)
$$

or

$$
d_{2, t} \equiv \frac{E_{t} \ln \left(\bar{y}_{t+1} / \pi_{t+1}\right)-\ln \left(R_{t}^{R} / \pi_{t+1} l_{t}\right)}{\sigma_{R}}, \quad d_{1, t} \equiv d_{2, t}+\sigma_{R}
$$

Recall that $\bar{y}_{t+1} \equiv \kappa\left(p_{t+1}^{R} y_{t+1}^{R}+q_{t+1}(1-\delta) k_{t}\right)$ so it can be substituted back to get complete expressions. Then $\sigma_{R}^{2}=\operatorname{var}\left(\bar{y}_{t+1}\right)=\operatorname{var}\left(\kappa\left(p_{t+1}^{R} y_{t+1}^{R}+q_{t+1}(1-\delta) k_{t}\right)\right)$.

To solve for the first-order conditions, we differentiate the expected loan payment w.r.t. $k_{t}$ :

$$
\begin{aligned}
\frac{\partial E_{t} \min \left\{R_{t}^{R} l_{t}, \quad \bar{y}_{t+1}\right\}}{\partial k_{t}}= & \left(1-\Phi\left(d_{1, t}\right)\right) \frac{\partial E_{t} \bar{y}_{t+1}}{\partial k_{t}} \\
& -E_{t} \bar{y}_{t+1} \frac{\partial \Phi\left(d_{1, t}\right)}{\partial d_{1, t}} \frac{\partial d_{1, t}}{\partial k_{t}}+R_{t}^{R} l_{t} \frac{\partial \Phi\left(d_{2, t}\right)}{\partial d_{2, t}} \frac{\partial d_{2, t}}{\partial k_{t}} \\
= & \left(1-\Phi\left(d_{1, t}\right)\right) \frac{\partial E_{t} \bar{y}_{t+1}}{\partial k_{t}}
\end{aligned}
$$

where the proof of the last expression comes from by using $\frac{\partial d_{1, t}}{\partial k_{t}}=\frac{\partial d_{2, t}}{\partial k_{t}}$ and computing the following:

$$
\begin{aligned}
& -E_{t}\left(\bar{y}_{t+1}\right) \Phi^{\prime}\left(d_{1, t}\right)+R_{t}^{R} l_{t} \Phi^{\prime}\left(d_{2, t}\right) \\
= & -e^{\ln \left(E_{t} \bar{y}_{t+1}\right)} \Phi^{\prime}\left(d_{1, t}\right)+e^{\ln \left(R_{t}^{R} l_{t}\right)} \Phi^{\prime}\left(d_{2, t}\right) \\
= & -e^{\ln \left(E_{t} \bar{y}_{t+1}\right)} \frac{1}{\sqrt{2 \pi}} e^{-\frac{1}{2} d_{1, t}^{2}}+e^{\ln \left(R_{t}^{R} l_{t}\right)} \frac{1}{\sqrt{2 \pi}} e^{-\frac{1}{2} d_{2, t}^{2}} \\
= & -e^{\ln \left(E_{t} \bar{y}_{t+1}\right)} \frac{1}{\sqrt{2 \pi}} e^{-\frac{1}{2}\left(d_{2, t}^{2}+2 d_{2, t} \sigma_{R}+\sigma_{F, t}^{2}\right)}+e^{\ln \left(R_{t}^{R} l_{t}\right)} \frac{1}{\sqrt{2 \pi}} e^{-\frac{1}{2} d_{2, t}^{2}} \\
= & -e^{\ln \left(E_{t} \bar{y}_{t+1}\right)} \frac{1}{\sqrt{2 \pi}} e^{-\frac{1}{2} d_{2, t}^{2}} e^{-\left(d_{2, t} \sigma_{R}+\frac{1}{2} \sigma_{F, t}^{2}\right)}+e^{\ln \left(R_{t}^{R} l_{t}\right)} \frac{1}{\sqrt{2 \pi}} e^{-\frac{1}{2} d_{2, t}^{2}} \\
= & -e^{\ln \left(E_{t} \bar{y}_{t+1}\right)} \frac{1}{\sqrt{2 \pi}} e^{-\frac{1}{2} d_{2, t}^{2}} e^{-E_{t}\left(\ln \bar{y}_{t+1}\right)-\ln \left(R_{t}^{R} l_{t}\right)+\frac{1}{2} \sigma_{F, t}^{2}}+e^{\ln \left(R_{t}^{R} l_{t}\right)} \frac{1}{\sqrt{2 \pi}} e^{-\frac{1}{2} d_{2, t}^{2}} \\
= & \frac{1}{\sqrt{2 \pi}} e^{-\frac{1}{2} d_{2, t}^{2}}\left[-e^{\ln \left(E_{t} \bar{y}_{t+1}\right)} e^{-\left(\ln \left(E_{t} \bar{y}_{t+1}\right)-\frac{1}{2} \sigma_{F, t}^{2}-\ln \left(R_{t}^{R} l_{t}\right)+\frac{1}{2} \sigma_{F, t}^{2}\right)}+e^{\ln \left(R_{t}^{R} l_{t}\right)}\right] \\
= & -\frac{1}{\sqrt{2 \pi}} e^{-\frac{1}{2} d_{2, t}^{2}} e^{\ln \left(R_{t}^{R} l_{t}\right)}+e^{\ln \left(R_{t}^{R} l_{t}\right)} \frac{1}{\sqrt{2 \pi}} e^{-\frac{1}{2} d_{2, t}^{2}} \\
= & 0,
\end{aligned}
$$


In this derivation we use the results for log-normal variables such as $E_{t} \ln \left(\bar{y}_{t+1}\right)=\ln \left(E_{t} \bar{y}_{t+1}\right)-\frac{1}{2} \sigma_{R}^{2}$ and and the definition of $d_{1, t}$. Substituting a definition for $\bar{y}_{t+1}$ back gives

$$
\frac{\partial E_{t} \min \left\{\frac{R_{t}^{R}}{\pi_{t+1}} l_{t}, \quad \kappa\left(p_{t+1}^{R} y_{t+1}^{R}+q_{t+1}(1-\delta) k_{t}\right)\right\}}{\partial k_{t}}=\left(1-\Phi\left(d_{1, t}\right)\right) \frac{\partial E_{t} \kappa\left(p_{t+1}^{R} y_{t+1}^{R}+q_{t+1}(1-\delta) k_{t}\right)}{\partial k_{t}}
$$

Similarly it can be shown that

$$
\frac{\partial E_{t} \min \left\{\frac{R_{t}^{R}}{\pi_{t+1}} l_{t}, \quad \kappa\left(p_{t+1}^{R} y_{t+1}^{R}+q_{t+1}(1-\delta) k_{t}\right)\right\}}{\partial h_{t}}=\left(1-\Phi\left(d_{1, t}\right)\right) \frac{\partial E_{t} \kappa\left(p_{t+1}^{R} y_{t+1}^{R}\right)}{\partial h_{t}}
$$

\section{B: Debt overhang in the banking sector with preferential shares}

If new equity is issued as preferential shares, new shareholders become senior to old shareholders. We model that by describing expected returns to new shareholders as a difference between total expected returns after paying depositors and what old shareholders can get in expectation. The contracted nominal return on new equity $E_{j, t}$ now would be defined as $R_{t}^{e}$. Expected returns to all shareholders (including those who buy preferential shares):

$$
\begin{aligned}
& E_{t} \beta \Lambda_{t, t+1}\left\{\omega_{j, t+1} r_{t}^{L T} l_{t}^{L T}\right. \\
& -E_{t} \beta \Lambda_{t, t+1}\left\{\left(1-\Phi\left(d_{1, t}\right)\right)\left(\omega_{j, t+1} r_{t}^{L T} l_{t}^{L T}\right)\right\} \\
& -E_{t} \beta \Lambda_{t, t+1}\left\{\Phi\left(d_{2, t}\right)\left(\frac{R_{t}}{\pi_{t+1}}(1-\gamma)\left(l_{j, t}+l_{t}^{L T}\right)-\frac{R_{j, t}^{L}}{\pi_{t+1}} l_{j, t}\right)\right\}
\end{aligned}
$$

where

$$
d_{2, t} \equiv \frac{E_{t} \ln \left(\omega_{j, t+1} r_{t}^{L T} l_{t}^{L T}\right)-E_{t} \ln \left(\frac{R_{t}}{\pi_{t+1}}(1-\gamma)\left(l_{j, t}+l_{t}^{L T}\right)-\frac{R_{j, t}^{L}}{\pi_{t+1}} l_{j, t}\right)}{\sigma_{B}}
$$

and

$$
d_{1, t} \equiv d_{2, t}+\sigma_{B}
$$

Expected returns to old shareholders: 


$$
\begin{aligned}
& E_{t} \beta \Lambda_{t, t+1}\left\{\omega_{j, t+1} r_{t}^{L T} l_{t}^{L T}\right. \\
& \quad-E_{t} \beta \Lambda_{t, t+1}\left\{\left(1-\Phi\left(\tilde{d}_{1, t}\right)\right)\left(\omega_{j, t+1} r_{t}^{L T} l_{t}^{L T}\right)\right\} \\
& \quad-E_{t} \beta \Lambda_{t, t+1}\left\{\Phi\left(\tilde{d}_{2, t}\right)\left(\frac{R_{t}}{\pi_{t+1}}(1-\gamma)\left(l_{j, t}+l_{t}^{L T}\right)+\frac{R_{t}^{e}}{\pi_{t+1}} \gamma l_{j, t}-\frac{R_{j, t}^{L}}{\pi_{t+1}} l_{j, t}\right)\right\}
\end{aligned}
$$

Notice that the distance to default that old shareholders now take into account is

$$
\tilde{d}_{2, t} \equiv \frac{E_{t} \ln \left(\omega_{j, t+1} r_{t}^{L T} l_{t}^{L T}\right)-E_{t} \ln \left(\frac{R_{t}}{\pi_{t+1}}(1-\gamma)\left(l_{j, t}+l_{t}^{L T}\right)+\frac{R_{t}^{e}}{\pi_{t+1}} \gamma l_{j, t}-\frac{R_{j, t}^{L}}{\pi_{t+1}} l_{j, t}\right)}{\sigma_{B}}
$$

and

$$
\tilde{d}_{1, t} \equiv \tilde{d}_{2, t}+\sigma_{B}
$$

Then expected returns to new shareholders would be given as the difference between expected ret urns to all shareholders in equation (15) and expected returns to old shareholders in equation (16) and would determine equilibrium $\frac{R_{t}^{e}}{\pi_{t+1}}$ :

$$
\begin{aligned}
e_{j, t}=E_{t} \beta \Lambda_{t, t+1}\left\{\left(1-\Phi\left(\tilde{d}_{1, t}\right)\right)\left(\omega_{j, t+1} r_{t}^{L T} l_{t}^{L T}\right)\right\} \\
+E_{t} \beta \Lambda_{t, t+1}\left\{\Phi\left(\tilde{d}_{2, t}\right)\left(\frac{R_{t}}{\pi_{t+1}}(1-\gamma)\left(l_{j, t}+l_{t}^{L T}\right)+\frac{R_{t}^{e}}{\pi_{t+1}} \gamma l_{j, t}-\frac{R_{j, t}^{L}}{\pi_{t+1}} l_{j, t}\right)\right\} \\
-E_{t} \beta \Lambda_{t, t+1}\left\{\left(1-\Phi\left(d_{1, t}\right)\right)\left(\omega_{j, t+1} r_{t}^{L T} l_{t}^{L T}\right)\right\} \\
-E_{t} \beta \Lambda_{t, t+1}\left\{\Phi\left(d_{2, t}\right)\left(\frac{R_{t}}{\pi_{t+1}}(1-\gamma)\left(l_{j, t}+l_{t}^{L T}\right)-\frac{R_{j, t}^{L}}{\pi_{t+1}} l_{j, t}\right)\right\}
\end{aligned}
$$

Or

$$
\begin{aligned}
e_{j, t}=E_{t} \beta \Lambda_{t, t+1}\left\{\left(\Phi\left(d_{1, t}\right)-\Phi\left(\tilde{d}_{1, t}\right)\right)\left(\omega_{j, t+1} r_{t}^{L T} l_{t}^{L T}\right)\right\} \\
+E_{t} \beta \Lambda_{t, t+1}\left\{\Phi\left(\tilde{d}_{2, t}\right) \frac{R_{t}^{e}}{\pi_{t+1}} \gamma l_{j, t}\right\} \\
-E_{t} \beta \Lambda_{t, t+1}\left\{\left(\Phi\left(d_{2, t}\right)-\Phi\left(\tilde{d}_{2, t}\right)\right)\left(\frac{R_{t}}{\pi_{t+1}}(1-\gamma)\left(l_{j, t}+l_{t}^{L T}\right)-\frac{R_{j, t}^{L}}{\pi_{t+1}} l_{j, t}\right)\right\}
\end{aligned}
$$

The first order condition for new loans can derived from maximizing returns to old shareholders (equation 16) and is now: 


$$
\begin{aligned}
l_{j, t}: \quad & \beta E_{t} \Lambda_{t, t+1}\left\{\Phi\left(\tilde{d}_{2, t}\right)\left\{\frac{R_{j, t}^{L}}{\pi_{t+1}}-(1-\gamma) \frac{R_{t}}{\pi_{t+1}}-\gamma \frac{R_{t}^{e}}{\pi_{t+1}}\right\}\right\} \\
& -\beta E_{t} \Lambda_{t, t+1}\left\{\frac{\Phi^{\prime}\left(\tilde{d}_{2, t}\right)}{\sigma_{B}}\left\{\frac{R_{j, t}^{L}}{\pi_{t+1}}-(1-\gamma) \frac{R_{t}}{\pi_{t+1}}-\gamma \frac{R_{t}^{e}}{\pi_{t+1}}\right\}\right\}=0
\end{aligned}
$$

\section{C: The baseline model with flexible labor demand}

In simulation exercises, when we relax the assumption of predetermined labor supply, we make the following modifications to the model. Firstly, we assume that the only input for financially constrained firms' production is capital. Second, we introduce a new layer of production firms and call them intermediate firms. These firms combine financially constrained firms' production with labor and sell homogeneous goods to retail firms. The novel type of firms is not subject to financial frictions.

Then the financially constrained firm's problem changes accordingly. The firm's borrowing decision depends on the firm's expected working capital needs such that in the beginning of period $t$ the following condition holds:

$$
E_{t-1}\left\{L_{i, t}\right\}=E_{t-1}\left\{\rho\left(Q_{t} k_{i, t}\right)\right\}
$$

Or, units of composite goods,

$$
E_{t-1}\left\{l_{i, t}\right\}=E_{t-1}\left\{\rho\left(q_{t} k_{i, t}\right)\right\}
$$

Definition of $P_{t+1}^{R} y_{i, t+1}^{R}$ changes in the following way: $P_{t+1}^{R} y_{i, t+1}^{R}=P_{t+1}^{R} z_{t+1} \theta_{i, t+1} k_{i, t}$.

After shocks take place, the generation of firms $t$ will solve the profit maximization problem taking the loan as given. They will sell goods at the competitive price $P_{t+1}^{R}$ which is defined $p_{t+1}^{R}$, if expressed in units of composite goods. The profit optimization problem of a financially constrained firm $i$ will be the following:

$$
\begin{aligned}
\max _{\left\{k_{i, t}\right\}} & E_{t} \beta \Lambda_{t, t+1}\left\{p_{t+1}^{R} y_{i, t+1}^{R}+q_{t+1}(1-\delta) k_{i, t}\right\} \\
& -E_{t} \beta \Lambda_{t, t+1} \min \left\{\frac{R_{i, t}^{R}}{\pi_{t+1}} l_{i, t}, \quad \kappa\left(p_{t+1}^{R} y_{i, t+1}^{R}+q_{t+1}(1-\delta) k_{i, t}\right)\right\} \\
& +l_{i, t}+z_{i, t}-\left(q_{t} k_{i, t}\right)
\end{aligned}
$$

s.t.

$$
E_{t-1}\left\{l_{i, t}\right\}=E_{t-1}\left\{\left(q_{t} k_{i, t}\right)\right\}
$$

The corresponding first-order condition is: 


$$
\begin{aligned}
k_{i, t}: & E_{t} \beta \Lambda_{t, t+1}\left\{p_{t+1}^{R} \frac{\partial y_{i, t+1}^{R}}{\partial k_{i, t}}+(1-\delta) q_{t+1}\right\} \\
& -\frac{\partial E_{t} \beta \Lambda_{t, t+1} E_{t} \min \left\{\frac{R_{i, t}^{R}}{\pi_{t+1}} l_{i, t}, \quad \kappa\left(p_{t+1}^{R} y_{i, t+1}^{R}+q_{t+1}(1-\delta) k_{i, t}\right)\right\}}{\partial k_{i, t}} \\
& =\frac{\partial \operatorname{cov}\left(\beta \Lambda_{t, t+1}, \quad \min \left\{\frac{R_{i, t}^{R} l_{i, t}}{\pi_{t+1}}, \quad \kappa\left(p_{t+1}^{R} y_{i, t+1}^{R}+q_{t+1}(1-\delta) k_{i, t}\right)\right\}\right)}{\partial k_{i, t}} \\
& +q_{t}
\end{aligned}
$$

If we substitute the expression for the expected value of loan repayment, we get:

$$
\begin{aligned}
k_{i, t}: & E_{t} \beta \Lambda_{t, t+1}\left\{p_{t+1}^{R} \frac{\partial y_{i, t+1}^{R}}{\partial k_{i, t}}+q_{t+1}(1-\delta)\right\} \\
& -E_{t} \beta \Lambda_{t, t+1}\left\{\left(1-\Phi\left(d_{1, t}\right)\right) \kappa\left(p_{t+1}^{R} \frac{\partial y_{i, t+1}^{R}}{\partial k_{i, t}}+q_{t+1}(1-\delta)\right)\right\} \\
& =\frac{\partial \operatorname{cov}\left(\beta \Lambda_{t, t+1}, \quad \min \left\{\frac{R_{i, t}^{R} l_{i, t}}{\pi_{t+1}}, \quad \kappa\left(p_{t+1}^{R} y_{i, t+1}^{R}+q_{t+1}(1-\delta) k_{i, t}\right)\right\}\right)}{\partial k_{i, t}} \\
& +q_{t}
\end{aligned}
$$

where

$$
d_{2, t} \equiv \frac{E_{t} \ln \left(\kappa\left(p_{t+1}^{R} y_{i, t+1}^{R}+q_{t+1}(1-\delta) k_{i, t}\right)\right)-E_{t} \ln \left(\frac{R_{i, t}^{R}}{\pi_{t+1}} l_{i, t}\right)}{\sigma_{R}}, \quad d_{1, t}=d_{2, t}+\sigma_{R}
$$

$\sigma_{R}^{2}$ is given by $\operatorname{var}\left(\pi_{t+1} \kappa\left(p_{t+1}^{R} y_{i, t+1}^{R}+q_{t+1}(1-\delta) k_{i, t}\right)\right)$.

Homogeneous goods produced by financially constrained firms are purchased as inputs by the new layer of competitive producers, intermediate producers. Intermediate producers hire labor and combine it with homogeneous goods produced by financially constrained firms by using the following technology:

$$
y_{t}^{I}=\left(y_{t}^{R}\right)^{\alpha} h_{t}^{1-\alpha}
$$

Recall that financially constrained firms' aggregate production function now is given by: $y_{t}^{R}=z_{t} k_{t-1}$. Produced goods are sold to retail firms at the nominal price $P_{t}^{I}$ immediately after production takes place. This gives two equilibrium conditions that can be derived from profit maximization with respect to inputs: 


$$
\begin{gathered}
y_{t}^{R}: \quad p_{t}^{R}=p_{t}^{I} \alpha\left(y_{t}^{R}\right)^{\alpha-1} h_{t}^{1-\alpha} \\
h_{t}: \quad w_{t}=p_{t}^{I}(1-\alpha)\left(y_{t}^{R}\right)^{\alpha} h_{t}^{-\alpha}
\end{gathered}
$$

In derivations we defined the following relative prices: $p_{t}^{I} \equiv P_{t}^{I} / P_{t}, p_{t}^{R} \equiv P_{t}^{R} / P_{t}$ and $w_{t} \equiv W_{t} / P_{t}$.

Marginal costs of the retail firms changes from being the price of financially constrained firms' goods to the price of intermediate goods.

This model version requires requires introducing the price $p_{t}^{I}$ and replacing equations (A.5)- (A.9) and (A.24) with:

$$
\begin{gathered}
E_{t} \beta \Lambda_{t, t+1}\left\{p_{t+1}^{R} \frac{\partial y_{i, t+1}^{R}}{\partial k_{i, t}}+q_{t+1}(1-\delta)\right\} \\
-E_{t} \beta \Lambda_{t, t+1}\left\{\left(1-\Phi\left(d_{1, t}\right)\right) \kappa\left(p_{t+1}^{R} \frac{\partial y_{i, t+1}^{R}}{\partial k_{i, t}}+q_{t+1}(1-\delta)\right)\right\} \\
=\frac{\partial \operatorname{cov}\left(\beta \Lambda_{t, t+1}, \quad \min \left\{\frac{R_{i, t}^{R} l_{i, t}}{\pi_{t+1}}, \quad \kappa\left(p_{t+1}^{R} y_{i, t+1}^{R}+q_{t+1}(1-\delta) k_{i, t}\right)\right\}\right)}{\partial k_{i, t}} \\
+q_{t} \\
d_{2, t} \equiv \frac{E_{t} \ln \left(\kappa\left(p_{t+1}^{R} A_{t+1} k_{t}+q_{t+1}(1-\delta) k_{i, t}\right)\right)-E_{t} \ln \left(\frac{R_{i, t}^{R}}{\pi_{t+1}} l_{i, t}\right)}{\sigma_{R}}, \quad d_{1, t}=d_{2, t}+\sigma_{R} \\
p_{t}^{R}=p_{t}^{I} \alpha\left(z_{t} k_{t-1}\right)^{\alpha-1} h_{t}^{1-\alpha} \\
w_{t}=p_{t}^{I}(1-\alpha)\left(z_{t} k_{t-1}\right)^{\alpha} h_{t}^{-\alpha} \\
E_{t}\left\{\frac{R_{t}^{L}}{\pi_{t+1}} l_{t}\right\}=\Phi\left(d_{2, t}^{R}\right) E_{t} R_{t}^{R} \frac{l_{t}}{\pi_{t+1}}+\left(1-\Phi\left(d_{1, t}^{R}\right)\right) E_{t} \kappa\left(p_{t+1}^{R} z_{t} k_{t}+q_{t+1}(1-\delta) k_{t}\right)
\end{gathered}
$$

The technology (equation A.17) is now given by:

$$
D_{t}^{H} y_{t}^{I}=\left(z_{t} k_{t-1}\right)^{\alpha} h_{t}^{1-\alpha}
$$


D: Equilibrium equations for the model with bank debt overhang and corporate debt overhang

The model is described by 26 endogenous variables:

$\left\{\lambda_{t}, c_{t}, h_{t}, w_{t}, d_{1, t}^{R}, d_{2, t}^{R}, R_{t}^{R}, p_{t}^{R}, R_{t}, R_{t}^{L}, l_{t}, \pi_{t}, \Lambda_{t, t+1}, k_{t}, i_{t}, q_{t}, \tilde{p}_{t}, D_{t}^{H}, y_{t}, F_{1, t}^{H}, F_{2, t}^{H}, d_{1, t}, d_{2, t}, p_{t}^{e}, d_{t}, e_{t}\right\}$

They are given by 26 equilibrium equations below.

Households

$$
\begin{gathered}
\lambda_{t}=\left(c_{t}\right)^{-\sigma} \\
\lambda_{t} w_{t}=\chi\left(h_{t}\right)^{\varphi} \\
\Lambda_{t, t+1} \equiv \frac{\lambda_{t+1}}{\lambda_{t}} \\
E_{t} \beta \Lambda_{t, t+1} \frac{R_{t}}{\pi_{t+1}}=1
\end{gathered}
$$

Financially constrained firms

$$
\begin{gathered}
E_{t} \beta \Lambda_{t, t+1}\left\{\left(1-\left(1-\Phi\left(d_{1, t}^{R}\right)\right)\right)\left(\alpha p_{t+1}^{R} A_{t+1} k_{t}^{\alpha-1} h_{t}^{1-\alpha}+q_{t+1}(1-\delta)\right)\right\}=q_{t} \\
E_{t} \beta \Lambda_{t, t+1}\left\{\left(1-\left(1-\Phi\left(d_{1, t}^{R}\right)\right)\right)(1-\alpha) p_{t+1}^{R} A_{t+1} k_{t}^{\alpha} h_{t}^{-\alpha}\right\}=w_{t} \\
E_{t-1}\left\{l_{t}\right\}=E_{t-1}\left\{\left(q_{t} k_{t}+w_{t} h_{t}\right)\right\} \\
d_{2, t}^{R} \equiv \frac{E_{t} \ln \left(\kappa\left(p_{t+1}^{R} y_{t+1}^{R}+q_{t+1}(1-\delta) k_{t}\right)\right)-E_{t} \ln \left(R_{t}^{R} \frac{l_{t}}{\pi_{t+1}}\right)}{\sigma_{R}} \\
d_{1, t}^{R} \equiv d_{2, t}^{R}+\sigma_{R}
\end{gathered}
$$

Capital producers

$$
\begin{gathered}
k_{t}=(1-\delta) k_{t-1}+\left(1-\Gamma\left(\frac{i_{t}}{i_{t-1}}\right)\right) i_{t} \\
\frac{1}{q_{t}}=\left(1-\frac{\gamma}{2}\left(\frac{i_{t}}{i_{t-1}}-1\right)^{2}\right)-\gamma\left(\frac{i_{t}}{i_{t-1}}-1\right) \frac{i_{t}}{i_{t-1}}+\gamma \beta E_{t} \Lambda_{t, t+1} \frac{q_{t+1}}{q_{t}}\left(\frac{i_{t+1}}{i_{t}}-1\right)\left(\frac{i_{t+1}}{i_{t}}\right)^{2}
\end{gathered}
$$

Intermediate firms 


$$
\begin{aligned}
& 1=\left(1-\omega^{H}\right)\left(\tilde{p}_{t}\right)^{1-\epsilon_{H}}+\omega^{H}\left(\frac{\left(\prod_{j=1}^{j=s} \pi_{t+j}^{a d j}\right)}{\pi_{t}}\right)^{1-\epsilon_{H}} \\
& D_{t}^{H}=\left(1-\omega^{H}\right)\left(\tilde{p}_{t}\right)^{-\epsilon_{H}}+\omega^{H}\left(\frac{\left(\prod_{j=1}^{j=s} \pi_{t+j}^{a d j}\right)}{\pi_{t}}\right)^{-\epsilon_{H}} D_{t-1}^{H} \\
& \tilde{p}_{t}=\frac{\epsilon_{H}}{\left(\epsilon_{H}-1\right)} \frac{F_{1, t}^{H}}{F_{2, t}^{H}} \\
& F_{1, t}^{H}=p_{t}^{R} y_{t}+E_{t} \omega^{H} \beta \Lambda_{t, t+1}\left(\frac{\pi_{t+1}}{\left(\prod_{j=1}^{j=s} \pi_{t+j}^{a d j}\right)}\right)^{\epsilon_{H}} F_{1, t+1}^{H} \\
& F_{2, t}^{H}=y_{t}+E_{t} \omega^{H} \beta \Lambda_{t, t+1}\left(\frac{\pi_{t+1}}{\left(\prod_{j=1}^{j=s} \pi_{t+j}^{a d j}\right)}\right)^{\epsilon_{H}-1} F_{2, t+1}^{H} \\
& D_{t}^{H} y_{t}=z_{t}\left(k_{t-1}\right)^{\alpha}\left(h_{t-1}\right)^{1-\alpha}
\end{aligned}
$$

\section{Banks}

$\beta E_{t} \Lambda_{t, t+1}\left\{\Phi\left(d_{2, t}\right)\left\{\frac{R_{j, t}^{L}}{\pi_{t+1}}-\frac{R_{t}}{\pi_{t+1}}(1-\gamma)\right\}-\frac{\Phi^{\prime}\left(d_{2, t}\right)}{\sigma_{B}}\left\{\frac{R_{j, t}^{L}}{\pi_{t+1}}-\frac{R_{t}}{\pi_{t+1}}(1-\gamma)\right\}\right\}=\gamma\left(1+2 \frac{\gamma l_{j, t}}{p_{t}^{e} n_{t}}\right)$

$$
\begin{gathered}
p_{j, t}^{e} e_{j, t}=\frac{e_{j, t}}{n_{t}+e_{j, t}} E_{t} \beta \Lambda_{t, t+1}\left\{\omega_{j, t+1} r_{t}^{L T} l_{t}^{L T}-\left(1-\Phi\left(d_{1, t}\right)\right)\left(\omega_{j, t+1} r_{t}^{L T} l_{t}^{L T}\right)\right\} \\
-\frac{e_{j, t}}{n_{t}+e_{j, t}} E_{t} \beta \Lambda_{t, t+1}\left\{\Phi\left(d_{2, t}\right)\left(\frac{R_{t}}{\pi_{t+1}}(1-\gamma)\left(l_{j, t}+l_{t}^{L T}\right)-\frac{R_{j, t}^{L}}{\pi_{t+1}} l_{j, t}\right)\right\} \\
n_{t}+p_{t}^{e} e_{t}=\gamma\left(l_{t}++l_{t}^{L T}\right) \\
n_{t}+p_{t}^{e} e_{t}+d_{t}+d_{t}^{L T}=l_{t}+l_{t}^{L T} \\
d_{2, t} \equiv \frac{E_{t} \ln \left(\omega_{j, t+1} r_{t}^{L T} l_{t}^{L T}\right)-E_{t} \ln \left(\frac{R_{t}}{\pi_{t+1}}(1-\gamma)\left(l_{j, t}+l_{t}^{L T}\right)-\frac{R_{j, t}^{L}}{\pi_{t+1}} l_{j, t}\right)}{\sigma_{B}}
\end{gathered}
$$




$$
\begin{gathered}
d_{1, t} \equiv d_{2, t}+\sigma_{B} \\
E_{t}\left\{\frac{R_{t}^{L}}{\pi_{t+1}} l_{t}\right\}=\Phi\left(d_{2, t}^{R}\right) E_{t} R_{t}^{R} \frac{l_{t}}{\pi_{t+1}}+\left(1-\Phi\left(d_{1, t}^{R}\right)\right) E_{t} \kappa\left(p_{t+1}^{R} y_{t+1}^{R}+q_{t+1}(1-\delta) k_{t}\right)
\end{gathered}
$$

Monetary policy

$$
\frac{R_{t}}{\bar{R}}=\left(\frac{R_{t-1}}{\bar{R}}\right)^{\gamma_{R}}\left(\frac{y_{t}}{\bar{y}}\right)^{\left(1-\gamma_{R}\right) \gamma_{Y}}\left(\frac{\pi_{t}}{\bar{\pi}}\right)^{\left(1-\gamma_{R}\right) \gamma_{\pi}} \exp \left(m p_{t}\right)
$$

Aggregate demand has to equal aggregate supply of composite goods

$$
y_{t}=c_{t}+i_{t}+g_{t}
$$

There are 4 exogenous variables: $z_{t}, \theta_{t}, m p_{t}, R_{t}^{L T}, g_{t}$.

If the model features risk shifting instead of bank debt overhang, conditions (A.18) and (A.19) have to be replaced with (4) and (5).

If the model features corporate debt overhang, but not bank debt overhang, conditions (A.18), (A.19),(A.22) and (A.23) have to be dropped and replaced with

$$
\beta E_{t} \Lambda_{t, t+1}\left\{\frac{R_{j, t}^{L}}{\pi_{t+1}}-\frac{R_{t}}{\pi_{t+1}}(1-\gamma)\right\}=\gamma\left(1+2 \frac{\gamma l_{j, t}}{p_{t}^{e} n_{t}}\right)
$$

and

$$
\begin{aligned}
p_{j, t}^{e} e_{j, t}=\frac{e_{j, t}}{n_{t}+e_{j, t}} E_{t} \beta \Lambda_{t, t+1}\left\{\omega_{j, t+1} r_{t}^{L T} l_{t}^{L T}\right\} & \\
-\frac{e_{j, t}}{n_{t}+e_{j, t}} E_{t} \beta \Lambda_{t, t+1} & \left\{\left(\frac{R_{t}}{\pi_{t+1}}(1-\gamma)\left(l_{j, t}+l_{t}^{L T}\right)-\frac{R_{j, t}^{L}}{\pi_{t+1}} l_{j, t}\right)\right\}
\end{aligned}
$$

The model without corporate debt overhang requires introducing a Lagrangian multiplier $\nu_{t}$ for the firm's maximization problem and replacing equations (A.5)- (A.9) and (A.24) with:

$$
\begin{gathered}
E_{t} \beta \Lambda_{t, t+1}\left\{\left(\alpha p_{t+1}^{R} A_{t+1} k_{t}^{\alpha-1} h_{t}^{1-\alpha}+q_{t+1}(1-\delta)\right)\right\}=\nu_{t} q_{t} \\
E_{t} \beta \Lambda_{t, t+1}\left\{(1-\alpha) p_{t+1}^{R} A_{t+1} k_{t}^{\alpha} h_{t}^{-\alpha}\right\}=\nu_{t} w_{t} \\
E_{t} \beta \Lambda_{t, t+1} \frac{R_{t}^{R}}{\pi_{t+1}}=\nu_{t}
\end{gathered}
$$




$$
\begin{gathered}
E_{t}\left\{l_{t}\right\}=E_{t}\left\{\left(q_{t} k_{t}+w_{t} h_{t}\right)\right\} \\
\frac{R_{t}^{L}}{\pi_{t+1}} l_{t}=R_{t}^{R} \frac{l_{t}}{\pi_{t+1}}
\end{gathered}
$$

\section{E: Tables and figures}

\begin{tabular}{ccc}
\hline Parameter & Description & Value \\
\hline \hline$\beta$ & Household's discount factor & 0.995 \\
$\sigma$ & Relative risk aversion & 1.6 \\
$\varphi$ & Labor supply elasticity & 4 \\
$\alpha$ & Capital share in production & 0.35 \\
$\delta$ & Capital depreciation rate & 0.025 \\
$\epsilon^{H}$ & E.o.S. between varieties of domestic goods & 11 \\
$\theta^{H}$ & Calvo parameter, domestic goods & 0.75 \\
$\kappa$ & Investment adjustment cost parameter & 4 \\
$z$ & Technology in SS & 1 \\
$\pi$ & Inflation in SS & 1.01 \\
$n$ & Working hours in SS & 0.3 \\
$\rho_{R}$ & Interest rate smoothing & 0.8 \\
$\alpha_{\pi}$ & Interest policy rule (inflation) & 1.5 \\
$\alpha_{y}$ & Interest policy rule (output) & 0.5 \\
\hline$\sigma_{R}$ & Volatility of firms' revenue & 0.08 \\
$\sigma_{B}$ & Volatility of returns on old loans & 0.08 \\
$\gamma$ & Bank capital requirement & 0.0765 \\
$\gamma$ & Bank capital requirement with flexible labor demand & 0.0843 \\
\hline
\end{tabular}

Table 1: Parameters

document 
Figure 13: Bank DO: Monetary policy of -5 p.p.
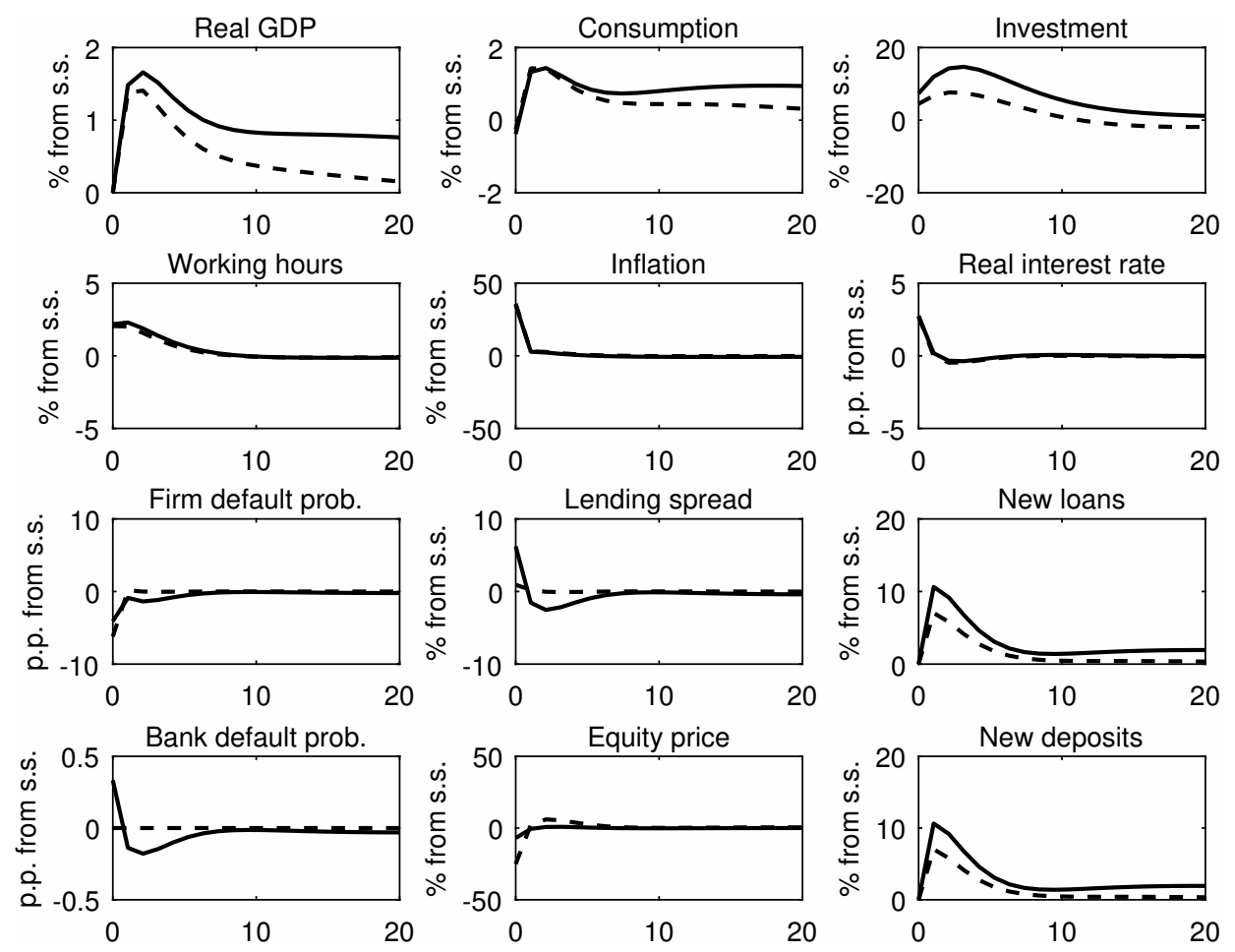

Note: Slotted line presents IRFs of the model with corporate debt overhang but without bank debt overhang. Solid line presents IRFs of the model with both bank debt overhang and corporate debt overhang. 
Figure 14: Firm DO: Monetary policy of -5 p.p. with flexible labor demand
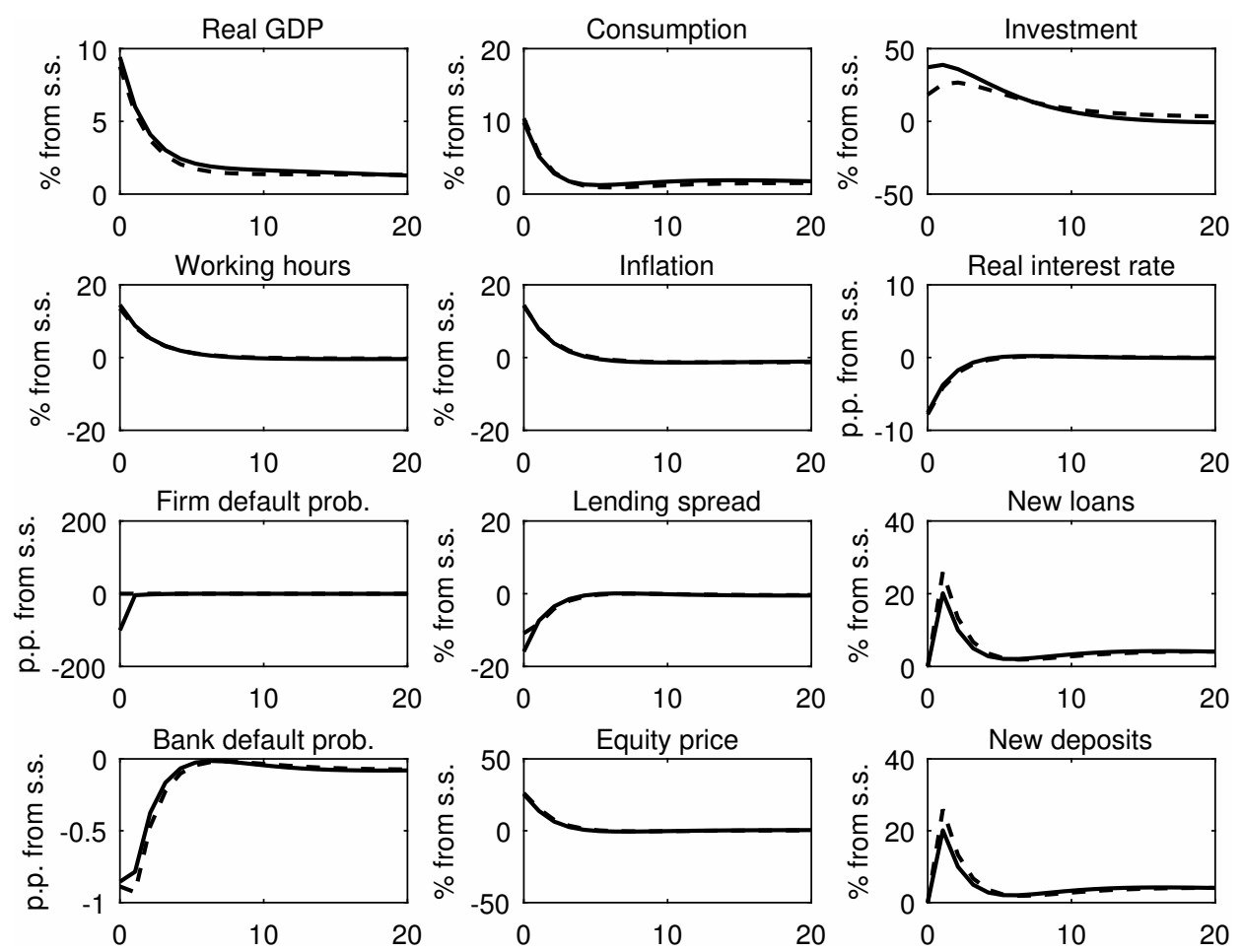

Note: Slotted line presents IRFs of the model with bank debt overhang but without corporate debt overhang. Solid line presents IRFs of the model with both bank debt overhang and corporate debt overhang. 
Figure 15: Bank DO: Monetary policy of -5 p.p. with flexible labor demand
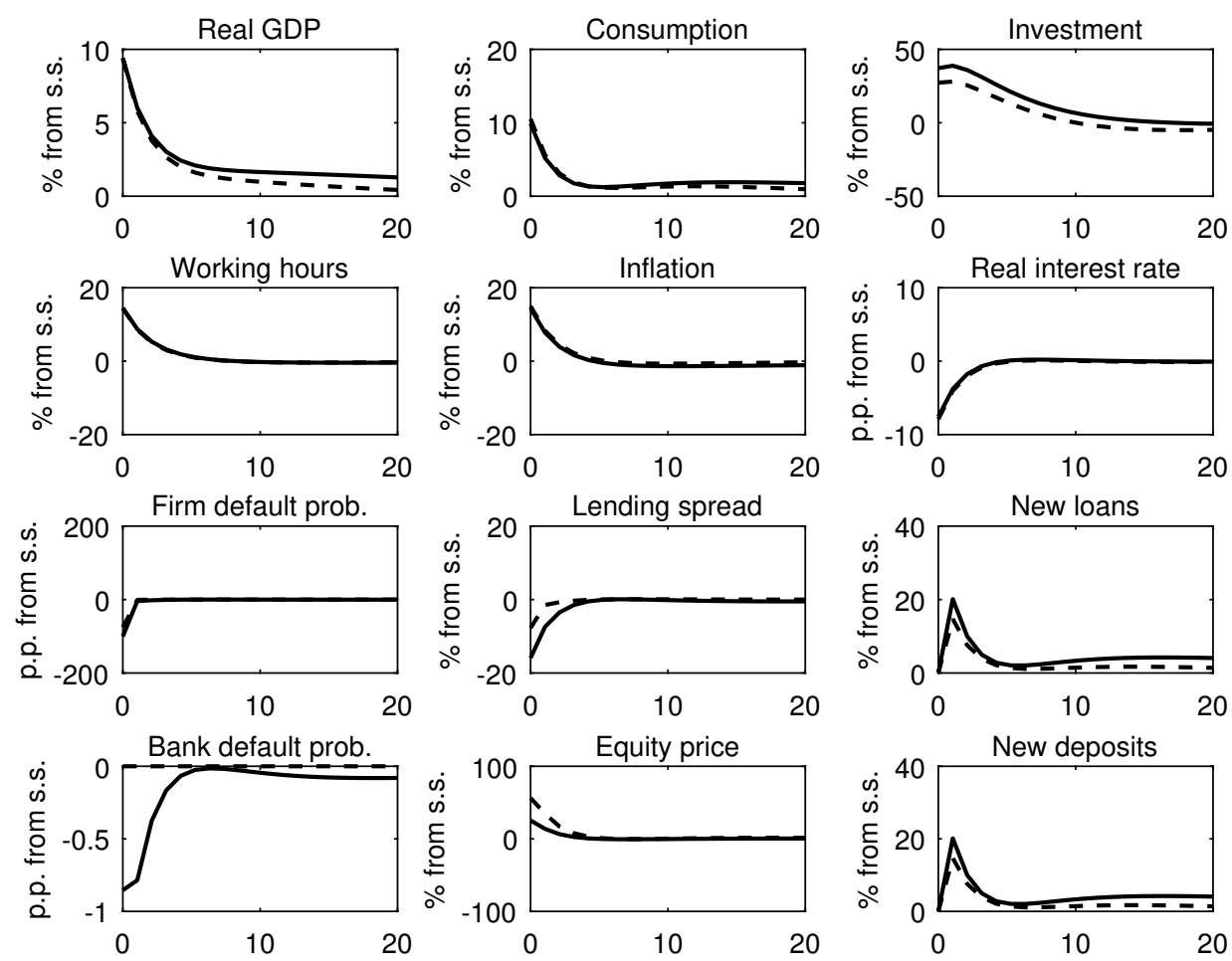

Note: Slotted line presents IRFs of the model with corporate debt overhang but without bank debt overhang. Solid line presents IRFs of the model with both bank debt overhang and corporate debt overhang. We assume flexible labor demand. 
Figure 16: Firm DO: Productivity shock of $-5 \%$ with flexible labor demand
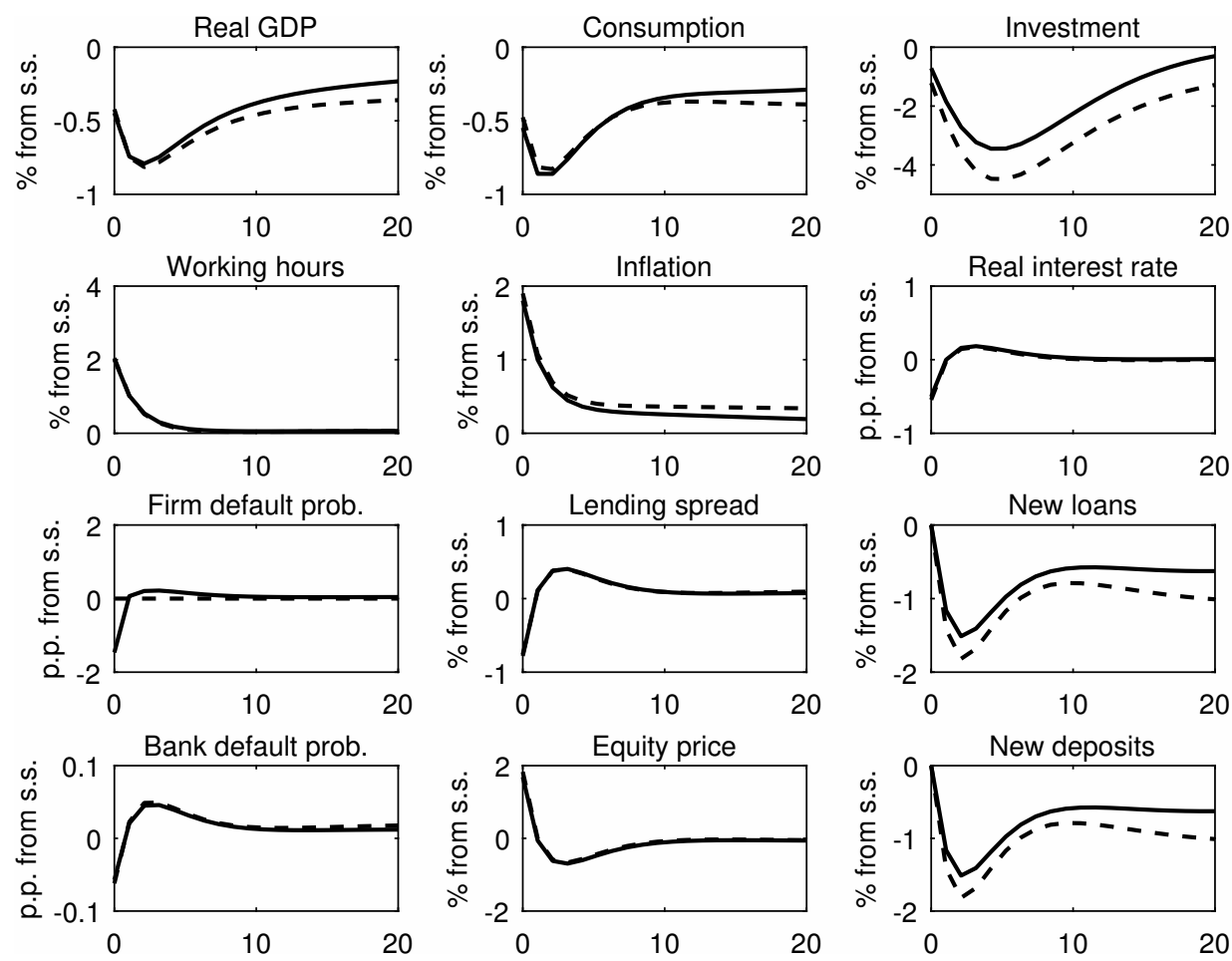

Note: Slotted line presents IRFs of the model with bank debt overhang but without corporate debt overhang. Solid line presents IRFs of the model with both bank debt overhang and corporate debt overhang. 
Figure 17: Bank DO: Productivity shock of $-5 \%$ with flexible labor demand
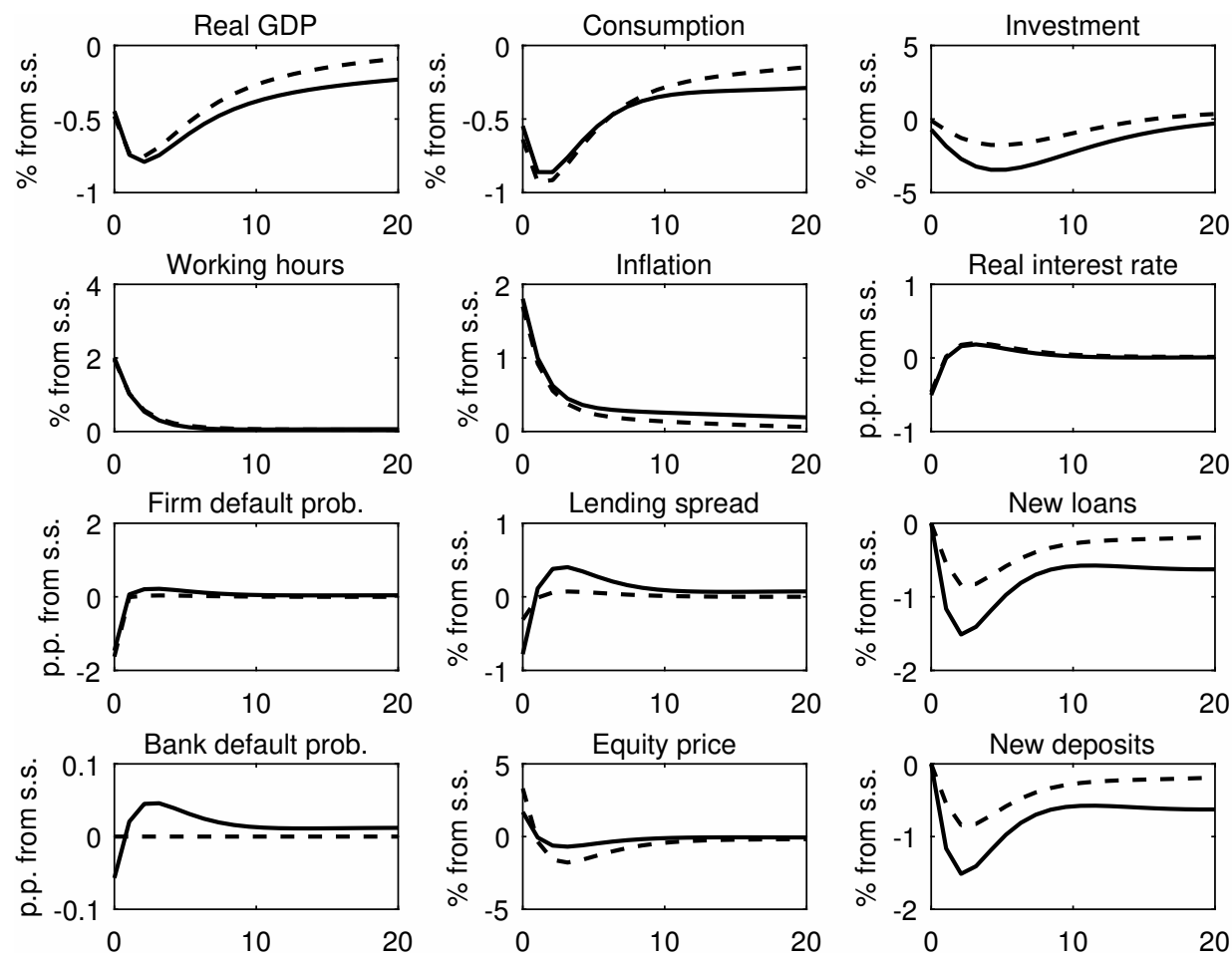

Note: Slotted line presents IRFs of the model with corporate debt overhang but without bank debt overhang. Solid line presents IRFs of the model with both bank debt overhang and corporate debt overhang. We assume flexible labor demand. 